\title{
REVIEW
}

\section{The Citrus Microbiome: From Structure and Function to Microbiome Engineering and Beyond}

\author{
Yunzeng Zhang, ${ }^{1}$ Pankaj Trivedi, ${ }^{2}$ Jin Xu, ${ }^{3}$ M. Caroline Roper,${ }^{4, \dagger}$ and Nian Wang ${ }^{5, \dagger}$ \\ ${ }^{1}$ Joint International Research Laboratory of Agriculture and Agri-Product Safety, the Ministry of Education of China, Yangzhou University, \\ Yangzhou 225009, China \\ ${ }^{2}$ Microbiome Network and Department of Agricultural Biology, Colorado State University, Fort Collins, CO, U.S.A. \\ ${ }^{3}$ Citrus Research and Education Center, Department of Plant Pathology, IFAS, University of Florida, Lake Alfred, FL, U.S.A. \\ ${ }^{4}$ Department of Microbiology and Plant Pathology, University of California, Riverside, CA, U.S.A. \\ ${ }^{5}$ Citrus Research and Education Center, Department of Microbiology and Cell Science, IFAS, University of Florida, Lake Alfred, FL, U.S.A.
}

Accepted for publication 21 January 2021.

\section{ABSTRACT}

Individual microbes often have defined relationships with their hosts that include beneficial, commensal, and pathogenic interactions. However, at the community level, plant microbiomes are considered to play a beneficial role in protecting the plant from potential pathogens, acquiring nutrients, and improving growth and production. Citrus is a globally important perennial fruit crop and its production faces many challenges. There has been tremendous interest in exploring the structure and function of the citrus microbiome and engineering the citrus microbiome to address various challenges. In this review, we summarized recent advances in understanding the citrus microbiome, including the composition and function of the microbiome in the rhizosphere, rhizoplane, endorhiza, and core members, and their functional traits. We conducted comparisons of the citrus root-associated microbiome with other plant root-associated microbiomes. We also present a perspective on how incoming pathogens interact with the resident microbial community and their outcomes. Despite the promising potential of the citrus microbiome to combat disease, harnessing the citrus microbiome for beneficial applications remains in its infancy. We envision that rapid development of high-throughput sequencing and multiomics technologies, artificial intelligence, consortia of microbes, genome editing technology, and high-throughput culturing present many exciting opportunities for citrus microbiome research and microbial engineering to improve citrus health and productivity.

Keywords: bacteriology, management, metagenomics, microbiome, microorganism, plant pathology, rhizosphere and phyllosphere
The plant microbiome is composed of different microorganisms, including bacteria, fungi, protists, archaea, and viruses (Mueller and Sachs 2015), which live externally on or internally in their host plants. Microbes that live outside their host plants are either epiphytic (i.e., living on the plant tissue surface) or rhizospheric (i.e., inhabiting the first several millimeters away from the roots within the soil).

†Corresponding author: N. Wang; nianwang@ufl.edu; and M. C. Roper; mcroper@ucr.edu

Y. Zhang, P. Trivedi, and J. Xu contributed equally to this work.

Funding: This work has been supported by the Florida Citrus Initiative Program, Citrus Research and Development Foundation, United States Department of Agriculture (USDA) MAC program, and USDA National Institute of Food and Agriculture awards 2018-70016-27412 and 2016-70016-24833 (to N. Wang). Y. Zhang is supported by the National Natural Science Foundation of China (31972318).

The author(s) declare no conflict of interest.

(C) 2021 The American Phytopathological Society
Conversely, microbes that colonize inside their host plant are called endophytic microbes. The relationship of individual microbes with their plant hosts is categorized into beneficial, commensal, and pathogenic. However, at the community level, plant microbiomes are considered to play a beneficial role, protecting the plant from potential pathogens and, at the same time, improving growth, health, and production, as well as conferring an adaptive advantage to plants (Berg et al. 2016; Haney et al. 2015). The plant root system, analogous to the animal gut, takes up nutrients and water and establishes intimate interactions with microbes (Hacquard et al. 2015). The root microbiome (the root-associated rhizosphere, rhizoplane, and endophytic microbes) (Fig. 1), one focus of plant microbiome research, performs many critical functions, including assisting with nutrient uptake, promoting plant growth by producing plant hormones, cycling carbon and nutrients, maintaining properties of soil, and protecting the host from pathogens (e.g., inducing immunity and niche occupation) (Berendsen et al. 2012; Bulgarelli et al. 2013). Another focus of plant microbiome research is the phyllosphere (i.e., aboveground parts of plants) microbiome. Leaves as plant organs are responsible for 
photosynthesis, and constitute the second largest plant microbial habitat compared with the root system, thus receiving most of the attention of phyllosphere studies. On the other hand, flowers and fruit are often important as consumer end products and entry points of many pathogens (An et al. 2020; Ference et al. 2018; Koczan et al. 2011) and, thus, are also of interest from both a research and economic perspective (Cui et al. 2021).

Citrus is one of the most important perennial fruit crops in the world. However, citrus production is facing many challenges, including nutrient limitation and diseases (Wang et al. 2017a). There are significant research efforts to understand the composition and function of the citrus microbiome and engineer the citrus microbiome to address various challenges in citriculture (Wang et al. 2017b). With recent, rapid developments of multiomics technologies such as amplicon-based sequencing, shotgun metagenomics, metatranscriptomics, and metabolomics (Nyholm et al. 2020; Sundin et al. 2016; Xu and Wang 2019), the structure and function of plant microbiomes are more and more clearly elucidated (Song et al. 2020). In this review, we summarize and discuss the current progress regarding the citrus microbiome, including the microbiome composition of citrus above- and belowground compartments, the core taxonomic and functional traits of the citrus microbiome, comparison of the citrus root-associated microbiome with other plant root-associated microbiomes, disease effect on the citrus microbiome, and potential and application of manipulation or engineering the citrus microbiome.

\section{RHIZOSPHERE MICROBIOME}

The rhizosphere, defined as the region around the root (Fig. 1), is a highly complex system that controls nutrient mobilization, improves plant productivity, and helps plants to resist biotic and abiotic stresses. In the rhizosphere, root exudates act as signal molecules and food sources for the selective recruitment of microbes from bulk soil (Bais et al. 2006). The diversity and structure of the

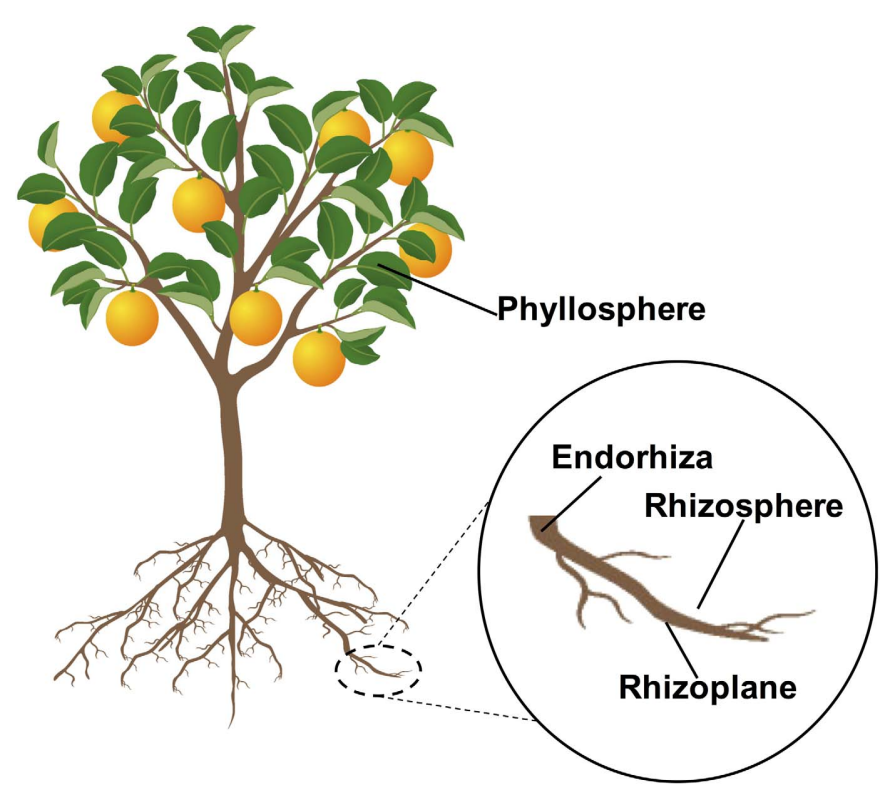

Fig. 1. Compartments of the citrus microbiome, including phyllosphere (aboveground portions of plants), rhizosphere (the area surrounding the plant root), rhizoplane (the root-soil interface), and endorhiza (internal compartments) (adapted, with permission, from Shutterstock.com). rhizosphere microbiome changes with plant developmental and health stages, genotypes, and soil conditions (Bulgarelli et al. 2015; Edwards et al. 2015; Hamonts et al. 2018; Herrera Paredes and Lebeis 2016; Schlaeppi et al. 2014). The interactions between rhizosphere-inhabiting microorganisms are dynamic, and fluctuations of metabolites exuded by plant roots help shape the root microbiota ( $\mathrm{Hu}$ et al. 2018; Lareen et al. 2016). Several studies have investigated the composition of the citrus rhizosphere microbiome compared with bulk soil (Trivedi et al. 2010, 2012; Xu et al. 2018) but few have elucidated the molecular features of rhizosphere colonization (Xu et al. 2018; Zhang et al. 2017) (Table 1).

Assessments of the root microbiome associated with citrus and related species using both cultivation- and noncultivation-based methods have revealed the enrichment of bacterial phyla Proteobacteria and Bacteroidetes in the rhizosphere as compared with bulk soils, whereas members affiliated with Cyanobacteria, Firmicutes, Acidobacteria, and Actinobacteria were depleted (Trivedi et al. 2010, 2012; Xu et al. 2018) (Table 1). The citrus rhizosphere was dominated by fungal phyla Ascomycota, Basidiomycota and, to a lesser extent, Glomeromycota; however the selective enrichment in the rhizosphere was only observed for genera distributed in Ascomycota ( $\mathrm{Xu}$ et al. 2018). Multiple archaeal phyla such as Crenarchaeota, Euryarchaeota, and Thaumarchaeota have been identified from the citrus rhizosphere, albeit their relative abundance was higher in the bulk soil than in the rhizosphere (Xu et al. 2018; Zhang et al. 2017). Phylum-level classification of the citrus microbiome under field conditions is similar from samples collected across the globe, suggesting host-driven recruitment through the selection of particular traits (Trivedi et al. 2020). The bacterial and fungal phyla enriched in the citrus rhizosphere are also found to be dominant in the rhizosphere of other plant species (Leach et al. 2017; Trivedi et al. 2020). This defined phylogenetic organization suggests that plant-associated microbiomes do not represent random assemblages but, instead, are structured by general rules for community assembly (Carlström et al. 2019; Trivedi et al. 2020).

In addition to bacteria, fungi, and archaea, the plant-associated microbial communities comprise other microbes such as protists, nematodes, and viruses (Leach et al. 2017; Mendes et al. 2013; Trivedi et al. 2020). Although protists, nematodes, and viruses are consistent members of the plant-associated microbiomes, we have very limited understanding of their structure and contribution to host performance. Recent studies have demonstrated that the protists can control the diversity and structure of the microbiome by predation effects and contribute to plant growth and fitness promotion (Geisen et al. 2016; Xiong et al. 2020). Xu et al. (2018) reported genes from protozoa and algae in the global citrus microbiome. A minute fraction $(0.02 \%)$ of the reads in the global citrus microbiome belonged to viruses (Xu et al. 2018). Morphological and microscopic studies have reported several species of nematodes from the citrus rhizosphere (Eisvand et al. 2019; Mankau and Gaspard 1986). The majority of the nematodes associated with the citrus rhizosphere belonged to genera Agamermis, Alaimus, Aphelenchus, Hemicriconemoides, Diphtherophora, Monoacrosporium, Nanidorus, Pratylenchus, Tylenchorhynchus, and Tylenchulus (Campos-Herrera et al. 2013; El-Borai et al. 2003; Mankau and Gaspard 1986) (Table 1). However, the functions and consequences of these abovementioned taxa on the citrus host remain elusive. In the future, targeted metagenomic-based approaches should be conducted to explore microbes other than bacteria and fungi in the citrus microbiome.

\section{RHIZOPLANE MICROBIOME}

The rhizoplane (i.e., root surface) (Fig. 1) acts as a critical gate that regulates microbial entry into the root (Reinhold-Hurek et al. 
2015; van der Heijden and Schlaeppi 2015). Therefore, the rhizoplane niche encounters a much stronger selection pressure imposed by the host compared with the rhizosphere (Reinhold-Hurek et al. 2015). Only certain microbial members are successfully enriched in the rhizoplane from the rhizosphere, which probably reflects the host's preference and adaptation strategies of the niche-differentiated microorganisms (Wang et al. 2020; Zhang et al. 2017). However, the citrus rhizoplane microbiome is still largely unexplored compared with the citrus rhizosphere microbiome, partially owing to the difficulty of the rhizoplane sample collection procedures, in which ultrasonication- or vigorous shaking-based treatments are required and many fewer microbial cells can be collected than in the rhizosphere sample collection procedure (Wang et al. 2020). Recently, Zhang et al. (2017) surveyed the composition of the citrus rhizoplane microbiome, in which hundreds of grams of citrus root cores were used for rhizoplane microbial cell collection; they further compared the taxonomic composition between the citrus rhizosphere and rhizoplane microbiomes using a shotgun metagenomics approach, and identified multiple bacterial genera affiliated with Proteobacteria (with Bradyrhizobium and Burkholderia being the two most dominant genera) that exhibited strong rhizosphere-to-rhizoplane enrichment patterns (Table 1). The majority of the rhizosphere-to-rhizoplane depleted taxa were affiliated with Actinobacteria, Acidobacteria, and Archaea. Zhang et al. (2017) further revealed the adaptation mechanisms of these rhizosphere-rhizoplane niche-differentiated microbes through metatranscriptomic analyses, and found that the functional attributes involved in microbe-plant and microbe-microbe interactions such as type III and type VI bacterial secretion systems and associated effectors, lipopolysaccharides, and chemotaxis are critical for microbes to enrich toward the rhizoplane niche under supervision of the plant host's immune system to enjoy the easy-to-use plantderived carbon sources, whereas the rhizosphere-to-rhizoplane depleted microbes are mostly autotrophic (Yu et al. 2019; Zhang et al. 2017). Of note, different microbial taxa may employ specific strategies to adapt in the rhizoplane; for example, the cell motilityassociated functional properties are important for Burkholderia spp. to successfully colonize in the rhizoplane compartment, whereas these functions do not seem to be critical for Bradyrhizobium spp. during the rhizosphere-to-rhizoplane enrichment process (Zhang et al. 2017). Recent developments in bioinformatics enable genomecentric meta-omics analyses and illustrate the mechanisms underlying niche adaptation of microbes at species-level or even strain-level resolution without cultivation (Goh et al. 2019; Zhang et al. 2020). For example, Zhang et al. (2020) recovered a near-complete Cellvibrio metagenome-assembled genome, which harbors multiple genes encoding enzymes responsible for plant cell degradation, and analyzed why Cellvibrio is enriched in the citrus rhizoplane from the rhizosphere, using an integrated metagenomics and metatranscriptomics approach. Differential gene expression analysis suggests that Cellvibrio downregulates its expression of plant cell wall degradation-associated genes but upregulates genes involved in repressing plant immune responses and antagonism against other microbes in the rhizoplane when compared with the rhizosphere (Zhang et al. 2020).

The majority of the citrus rhizosphere-to-rhizoplane enriched genera are frequently reported as plant-beneficial bacteria, indicating why these taxa are preferred by the citrus host and how these selected microbes contribute to plant health and fitness (ReinholdHurek et al. 2015; van der Heijden and Schlaeppi 2015; Zhang et al. 2017) (Table 1). Two citrus root-originated strains affiliated with Burkholderia, which is the second most dominant genus in the citrus rhizoplane microbiome and exhibits a strong rhizosphere-torhizoplane enrichment pattern, were found to exhibit a higher adaptation rate in the rhizoplane than in the rhizosphere by an inoculation experiment, consistent with the metagenomics-based results (Trivedi et al. 2011; Zhang et al. 2017). In vitro and in planta experiments demonstrate that both Burkholderia strains directly inhibit the growth of multiple citrus pathogens such as Alternaria alternata, Colletotrichum acutatum, Phyllosticta citricarpa, Phytophthora nicotianae, and Phytophthora palmivora, and may also help the citrus host resist other pathogens by inducing the systemic resistance of the citrus host (Riera et al. 2017, 2018; Zhang et al.

TABLE 1

Summary of the major findings of the citrus microbiome across compartments

\begin{tabular}{|c|c|c|}
\hline Compartment & Major finding & Reference \\
\hline \multirow{2}{*}{ Rhizosphere } & $\begin{array}{l}\text { Effects of huanglongbing (HLB) on the citrus } \\
\text { rhizosphere microbiome have been confirmed }\end{array}$ & $\begin{array}{l}\text { Ascunce et al. 2019; Trivedi et al. 2010, 2012; Zhang } \\
\text { et al. } 2017\end{array}$ \\
\hline & $\begin{array}{l}\text { Several species of nematodes from the citrus } \\
\text { rhizosphere have been found }\end{array}$ & $\begin{array}{l}\text { Campos-Herrera et al. 2013; Eisvand et al. 2019; } \\
\text { El-Borai et al. 2003; Mankau and Gaspard } 1986\end{array}$ \\
\hline \multirow[t]{2}{*}{ Rhizoplane } & $\begin{array}{l}\text { Multiple bacterial genera and their functional traits } \\
\text { exhibited strong rhizosphere-to-rhizoplane enrichment } \\
\text { patterns, which was affected by HLB }\end{array}$ & Zhang et al. 2017; Zhang et al. 2020 \\
\hline & $\begin{array}{l}\text { Multiple potential citrus beneficial microbes have been } \\
\text { found }\end{array}$ & $\begin{array}{l}\text { Blacutt et al. 2020; Riera et al. 2017, 2018; Zhang } \\
\text { et al. } 2020\end{array}$ \\
\hline Endorhiza & $\begin{array}{l}\text { Dominant phyla and beneficial microbes in the } \\
\text { endorhiza microbiome of citrus plants were identified; } \\
\text { HLB had a profound effect on the endorhiza } \\
\text { microbiome }\end{array}$ & $\begin{array}{l}\text { Ascunce et al. 2019; Bai et al. 2019; Blaustein et al. } \\
\text { 2017; Ginnan et al. 2020; Passera et al. 2018; } \\
\text { Trivedi et al. 2010, 2011 }\end{array}$ \\
\hline
\end{tabular}


2017). Genomic analyses of the two strains further identified the gene clusters involved in pathogen antagonism activities as well as other beneficial traits such as phosphate solubilization and phytohormone production (Riera et al. 2017). Cellvibrio is a member of the core citrus rhizosphere microbiome, and is further enriched in the citrus rhizoplane from the rhizosphere (Xu et al. 2018; Zhang et al. 2020; Zhang et al. 2017); genome-centric metagenomics and metatranscriptomics analyses show that Cellvibrio probably benefits the citrus host by antagonizing against the fungal pathogens, among other beneficial mechanisms such as auxin production (Zhang et al. 2020).

Until now, to the best of our knowledge, no cultivation-based study has been performed to investigate the beneficial functions of the citrus rhizoplane microbiome. Intriguingly, Blacutt et al. (2020) developed a high-throughput bacteria and fungi cultivation and identification pipeline to screen the potential beneficial microbes. However, certain slow-growing microbes such as Bradyrhizobium spp., were not identified in this study and previous cultivation-based studies (Blacutt et al. 2020; Giassi et al. 2016; Trivedi et al. 2011), demonstrating the necessity to further improve the cultivation-based approach. Nevertheless, culturomics and bioinformatics approaches may facilitate our understanding of how these plant-preferred microbes that are enriched in the rhizoplane from the rhizosphere contribute to citrus health and fitness.

\section{ENDORHIZA MICROBIOME}

The selective forces imposed by the plant host on the endorhiza niche (Fig. 1) are much stronger than the extracorporeal microhabitats (rhizosphere and rhizoplane) and the population of the microbes in the endorhiza microbiome are approximately fivefold decreased compared with the rhizosphere microbiome (Reinhold-Hurek et al. 2015; Wang et al. 2020). Recent studies on the citrus endorhiza microbiome were performed mainly via sequencing the $16 \mathrm{~S}$ ribosomal DNA (rDNA) hypervariable regions or cultivation-based approaches, with surface-disinfected roots as working materials (Bai et al. 2019; Passera et al. 2018; Trivedi et al. 2010, 2011). Proteobacteria, Firmicutes, and Actinobacteria are the most dominant phyla in the endorhiza microbiome of citrus plants, with beneficial genera such as Burkholderia, Variovoras, Bacillus, Brevibacillus, and Paenibacillus frequently reported, as revealed by both cultivation- and noncultivation-based studies (Bai et al. 2019; Passera et al. 2018; Trivedi et al. 2010, 2011) (Table 1). It was reported that a large fraction of the isolated citrus endorhiza bacteria harbor beneficial traits such as phosphorus solubilization, indole 3 -acetic acid production, nitrogen fixation, 1-aminocyclopropane-1carboxylate deaminase production, salicylic acid production, siderophore production, and chitinase production, indicating how the host-recruited endorhiza microbes contribute to citrus fitness (Trivedi et al. 2011). The composition of the citrus endorhiza microbiome in healthy citrus trees is relatively stable but plant diseases have a profound effect on the microbiome composition (Passera et al. 2018; Trivedi et al. 2010, 2011) (Table 1). The relative abundance of putatively beneficial bacteria in the microbiome is also decreased in diseased trees (Trivedi et al. 2011), demonstrating the hidden impact of pathogens on the microbiome, which is usually undeservedly neglected. However, the quantitative contribution of microbes in the endorhiza to plant health remains to be determined. Importantly, the majority of previous studies did not differentiate the citrus rhizoplane and endorhiza components during the sample collection procedures, in which the analyzed microbiome was collectively defined as the root microbiome (Ascunce et al. 2019; Blacutt et al. 2020; Blaustein et al. 2017).
Until now, metagenomics or metatranscriptomics studies have not been performed for the citrus endorhiza or the so-called root microbiome, possibly because of the difficulties of removing host DNA and RNA from that of the microbiome, which hampers our understanding of the endorhiza microbiome. Under this circumstance, comparative genomic analysis between the root-adapted microbes and their non-plant-associated taxonomic-related relatives is a promising approach to reveal the functional attributes critical for the microbes to adapt within the root endorhiza (Levy et al. 2018); moreover, high-throughput gene mutation and screening methods such as randomly barcoded transposon sequencing can further identify the individual genes and the pathways involved in the root niche adaptation of a given microbe (Cole et al. 2017). In addition, the rapidly developing methods of removing host DNA by lysing the host cells and degrading host DNA prior to microbial DNA purification (e.g., HostZERO Microbial DNA Kit) or depleting the host DNA by the DNA methylation difference between the host and the microbes (e.g., NEBNext Microbiome DNA Enrichment Kit) are promising to efficiently increase the percentage of microbial DNA in the total DNA to advance the metagenomic analyses of host-associated microbiomes (Heravi et al. 2020). Of note, Song and Xie (2020) developed a CRISPR-Cas system that can specifically recognize and degrade the plant-originated $16 \mathrm{~S}$ rDNA sequences from the mitochondrion and plastid and, hence, enable deeper 16S rDNA-based bacterial community profiling with lower cost.

\section{PHYLLOSPHERE MICROBIOME}

The phyllosphere niche is defined as the aboveground portions of a plant where microorganisms colonize (Liu et al. 2020) (Fig. 1). The microorganisms colonizing the phyllosphere are exposed to diverse abiotic (e.g., rainfall, heat, and UV radiation) and biotic (e.g., insect visitations, and microorganisms introduced by wind or other carriers) stresses and agricultural practices, in addition to immune response of the plant host (Carlström et al. 2019; Chen et al. 2020; Vorholt 2012). The citrus phyllosphere bacterial community is dominated by phyla Proteobacteria, Firmicutes, and Actinobacteria, which is similar to the citrus root-associated microbiome; however, the ratio between these phyla varies significantly among trees from different geographic locations, citrus cultivars, and health status (Blaustein et al. 2017; Ginnan et al. 2020) (Table 1). Moreover, the taxa Bacteroidetes was more abundant in the citrus leaf microbiome than in the citrus root-associated microbiome (Bai et al. 2019; Blaustein et al. 2017; Passera et al. 2018; $\mathrm{Wu}$ et al. 2020). The functional attributes critical for a healthy phyllosphere microbiome remain largely unknown because large-scale metagenomics or metatranscriptomics have not been performed on citrus phyllosphere communities. The studies coupled with functional microbiome studies will be important to understand the function of the microbiome on the leaf surface and inside the leaf, and how to utilize phyllosphere microbes to promote plant health and fitness.

\section{TAXONOMIC AND FUNCTIONAL COMPOSITION OF THE CORE CITRUS MICROBIOME}

Using persistence of the association as the criterion (e.g., a taxa detected in more than $75 \%$ of the tested individuals) (Xu et al. 2018), the "core microbiome" is defined as the group of microbes commonly found within a host's microbiome. The core microbiome has been elucidated for citrus rhizosphere, root, stem, and leaf compartments (Blaustein et al. 2017; Ginnan et al. 2020; Xu et al. 2018) (Fig. 2). These core microbiome members are postulated to 
play key roles in organizing the assembly of plant-associated microbiomes, rather than just promoting host plant growth (Toju et al. 2018). The core members of the citrus microbiome are diverse across compartments (Blaustein et al. 2017; Ginnan et al. 2020; Xu et al. 2018) (Fig. 2). Specifically, the core citrus bacterial community across compartments consists of the genera Sphingobium, Pseudomonas, Agrobacterium, Chitinophaga, Mesorhizobium, Steroidobacter, Cupriavidus, Dokdonella, Novosphingobium, Hylemonella, Rhizobium, Roseateles, Phenylobacterium, Devosia, Niastella, Rhodoplanes, Halomonas, Bacillus, Sphingomonas, and Streptomyces (Fig. 2 ). The core fungal rhizosphere microbiome is significantly less diverse than the bacterial counterpart and includes seven fungal genera affiliated with the divisions Ascomycota, Basidiomycota, and Glomeromycota (Ginnan et al. 2020; Xu et al. 2018) (Fig. 2). Multiple members affiliated with these core genera are known as plant beneficial microbes in other systems, and may aid in maintaining plant hormone balance, controlling root development, facilitating nutrition acquisition, and preventing disease manifestation in the plant host (Fravel et al. 2003; Lemanceau et al. 2017; Verbon and Liberman 2016). Interestingly, the abundant bacterial taxa in the core citrus microbiome are also found to be the dominant members of the rhizosphere of other plant species (Hamonts et al. 2018; Ofek-Lalzar et al. 2014; Walters et al. 2018; Yeoh et al. 2017), suggesting the existence of a universal core plant microbiome.

Thus far, core microbiota is defined based on taxonomy and functional aspects that drive the plant-microbiome interactions, including colonization, competition, and signaling. Due to the

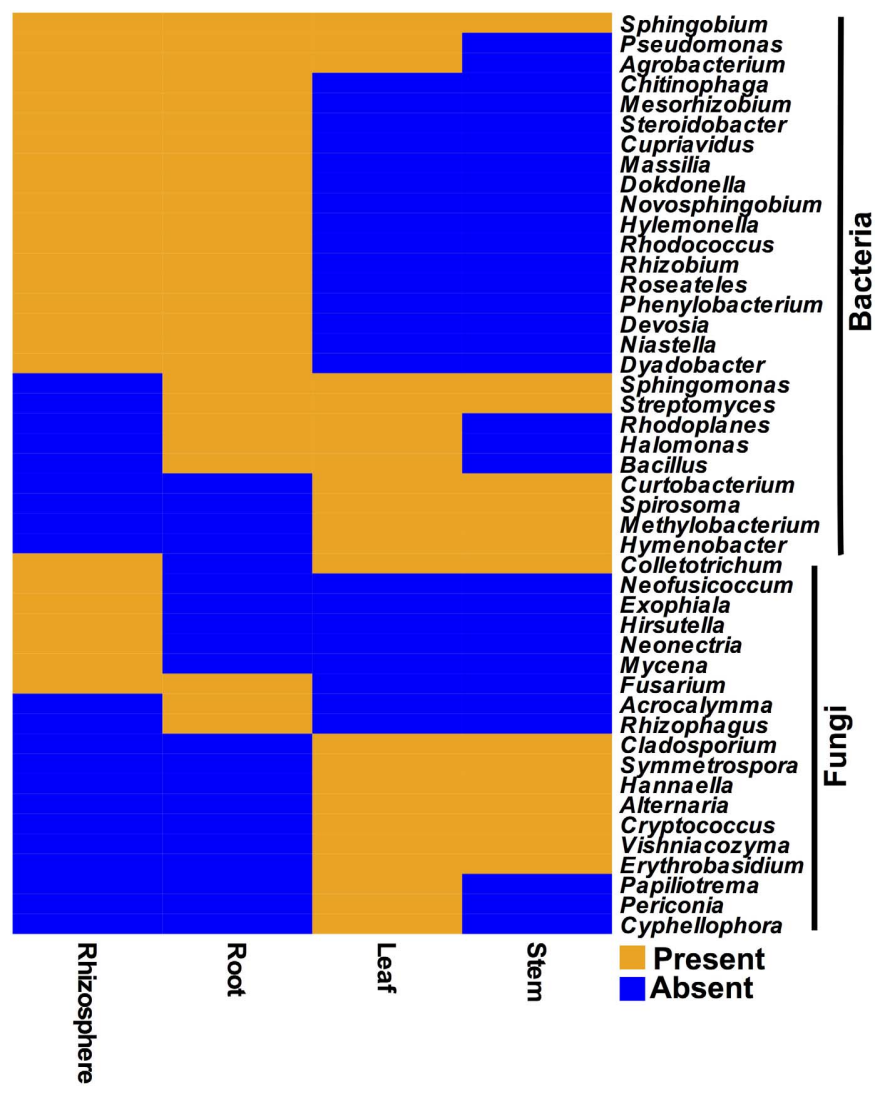

Fig. 2. Core citrus microbiome. The figure was generated with data from Blaustein et al. (2017), Xu et al. (2018), and Ginnan et al. (2020). Bacteria of the core microbiome only presented the overlapped genera among compartments. significance of functional traits of the plant-associated microbiome, an emphasis has been placed on determining the "core functional microbiome" of plant species at a global scale (Lemanceau et al. 2017). Previous studies reported the core functional traits of the citrus rhizosphere microbiome but not those of root and leaf microbiomes owing to the difficulties of removing host DNA and RNA from that of the microbiome. The core functional traits of the citrus rhizosphere microbiome are enriched in microbial traits mediating plant-microbe and microbe-microbe interactions, nutrient acquisition, and plant growth promotion ( $\mathrm{Xu}$ et al. 2018) (Fig. 3). A high number of transporters, including ATP-binding cassettes, phosphotransferase systems, and drug or metabolite transporters, that could import a broad range of plant-derived nutrients, are present in the citrus rhizosphere microbiome ( $\mathrm{Xu}$ et al. 2018) (Fig. 3), which probably allows fine tuning between the root exudates and microbial growth, thus enabling selective recruitment of rhizosphere microbiome from bulk soils (Trivedi et al. 2013, 2020). A strong positive selection in traits that are known to directly interact with the plant host such as the bacterial secretion systems and other outer surface proteins is an indication of the contribution of plant immune response in sculpting the citrus rhizosphere microbiome (Hacquard et al. 2017). The depletion of genes involved in carbon fixation and amino acid biosynthesis pathways in the rhizosphere compared with the bulk soil is indicative of the efficient utilization of plant-derived nutrients that further provides the selective advantage to colonize the nutrient-rich plant environment (Trivedi et al. 2020; Xu et al. 2018). Enrichment of transcription factors in the citrus rhizosphere indicates tight coordination of gene functions involved in metabolism, quorum sensing, motility, stress response, and host-microbe interactions. Genes involved in plant-growth promotion such as nutrient mobilization (e.g., phosphorus, nitrogen, and iron transport and utilization), induction of plant defense response (e.g., salicylate synthesis), and direct antagonism against pathogens (e.g., toxin and antimicrobial compound production) were enriched in the citrus rhizosphere (Fig. 3). These observations demonstrate the importance of microbiome-mediated functions in promoting plant health and performance.

\section{COMPARISON OF CITRUS ROOT-ASSOCIATED MICROBIOME WITH OTHER PLANT ROOT-ASSOCIATED MICROBIOMES}

We compared the microbiome composition between citrus and 14 other plant species (Bulgarelli et al. 2012, 2015; Cúcio et al. 2016; de Souza et al. 2016; Donn et al. 2015; Edwards et al. 2015; Gottel et al. 2011; Jin et al. 2017; Pérez-Jaramillo et al. 2017; Pfeiffer et al. 2017; Yergeau et al. 2015; Zarraonaindia et al. 2015; Zgadzaj et al. 2016) based on 16S rDNA sequencing data. We found that the abundant phyla in the citrus root-associated microbiome, including Proteobacteria, Actinobacteria, Acidobacteria, Bacteroidetes, Firmicutes, Gemmatimonadetes, Planctomycetes, Nitrospirae, Verrucomicrobia, and Spirochaetes, are also dominant in the 14 other plant species (Fig. 4). At a higher resolution, we identified 20 genera, including Pseudomonas, Flavobacterium, Steroidobacter, Nitrospira, Bacillus, Bradyrhizobium, Burkholderia, Rhizobium, Mesorhizobium, Devosia, Sphingomonas, Flavisolibacter, Paenibacillus, Geobacter, Hyphomicrobium, Cellvibrio, Novosphingobium, Pedomicrobium, Phenylobacterium, and Bdellovibrio, that are dominant across all the plant species (Fig. 5). The implications of the common abundant plant root-associated taxa remain to be explored. 


\section{DISEASE EFFECT ON CITRUS MICROBIOME}

Plant-microbe interactions are key drivers of plant performance and ecology. Because of its enormous economic importance, plant-pathogen interaction is a particular focused aspect of plant-microbe interactions and has been extensively studied. Most studies in this field incorporate a "single species and monoculture" way of thinking and are directed toward a better understanding of the molecular mechanism of plant pathogen and plant immune responses and have shed valuable insight into how parasitic or beneficial microbes interact with their plant hosts (Trivedi et al. 2016). However, in nature, microbes live in constant association with other microbial species, directly or indirectly interacting, and creating multispecies communities. The pathogen's introduction

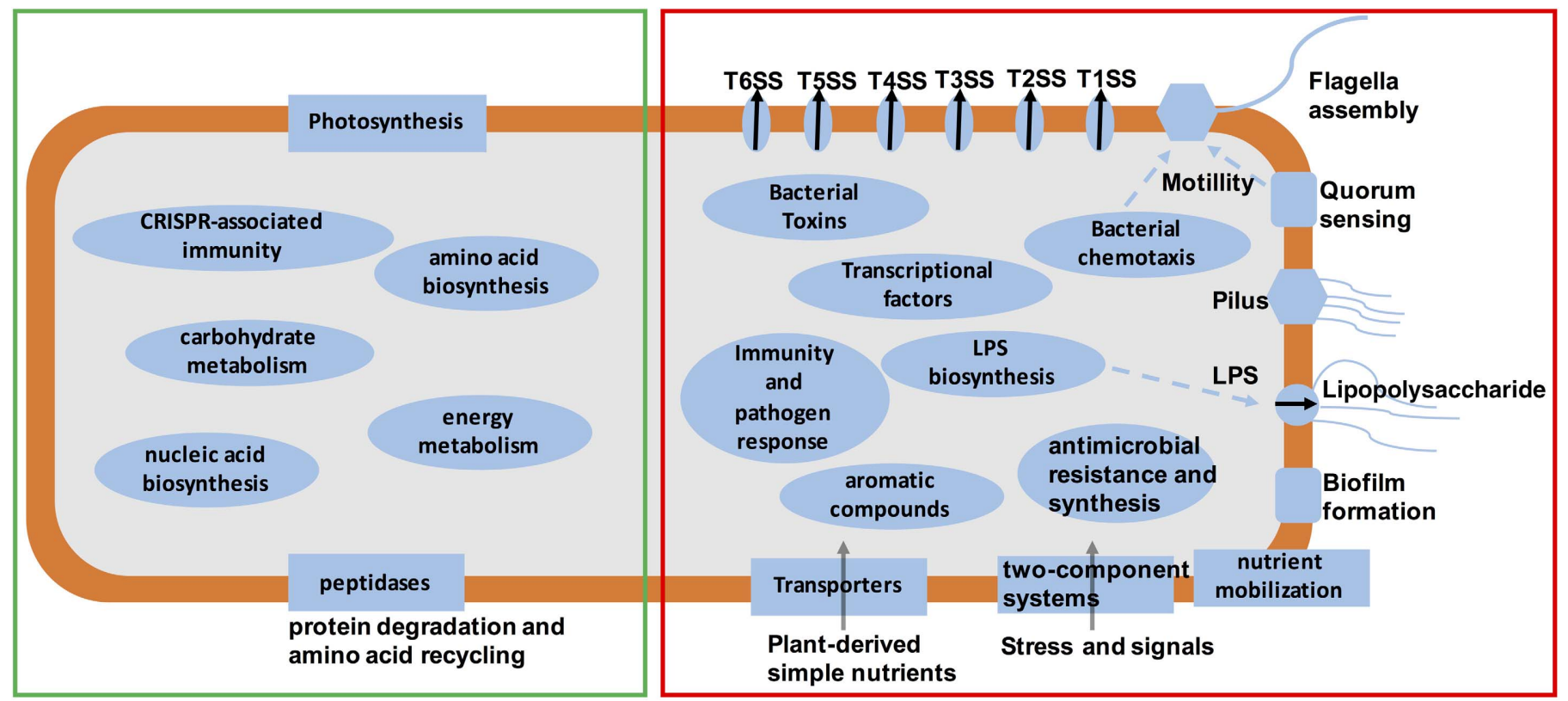

Fig. 3. Core functional traits of citrus microbiome. The figure was generated with data from Xu et al. (2018). The left side represents the depleted functional traits and the right side represents the core rhizosphere functional traits. T6SS $=$ type 6 secretion system, T5SS $=$ type 5 secretion system, and so on.

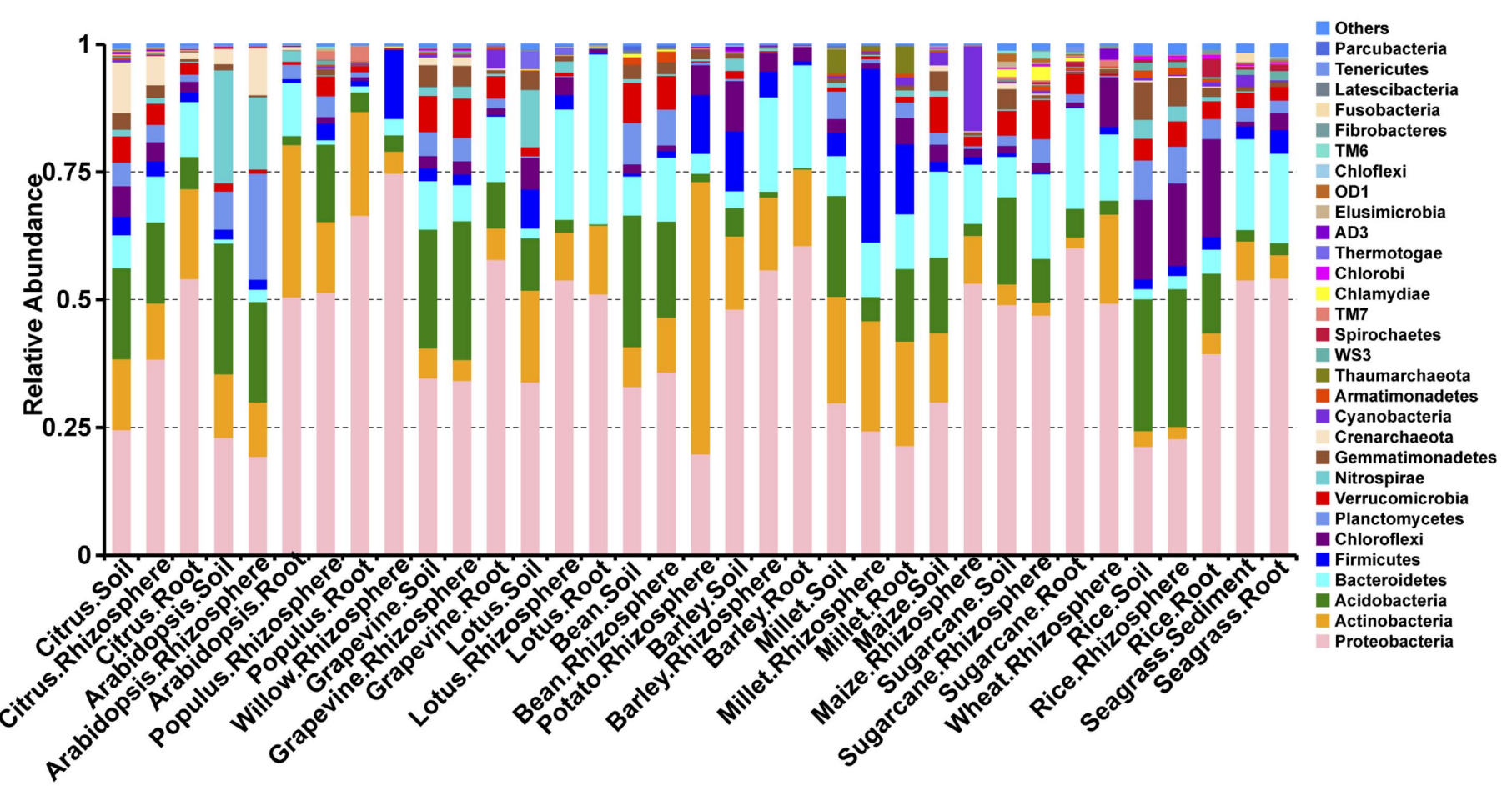

Fig. 4. Taxonomic distribution of plant root-associated microbiomes of 15 plant species at the phylum level identified using the $16 \mathrm{~S}$ data. Data were derived from public data sets (Bulgarelli et al. 2012, 2015; Cúcio et al. 2016; de Souza et al. 2016; Donn et al. 2015; Edwards et al. 2015; Gottel et al. 2011; Jin et al. 2017; Pérez-Jaramillo et al. 2017; Pfeiffer et al. 2017; Xu et al. 2018; Yergeau et al. 2015; Zarraonaindia et al. 2015; Zgadzaj et al. 2016). 
has the potential to disturb the fine-tuned interactions between the plant and its associated microbiome (Araújo et al. 2002; Ginnan et al. 2020; Trivedi et al. 2012). Changes in the community structure and interactions of the native microbiome and pathogen production of its own virulence factors can lead to a rapid decline in the host health and productivity (Müller et al. 2016; Schlaeppi and Bulgarelli 2015; Trivedi et al. 2016). Elucidation of the possible interactions between incoming pathogens and the native residents in the microbiome and their outcomes has been showing great promise for plant fitness promotion, and gaining more and more interest (Kwak et al. 2018).

Previous studies have examined the effect of perturbations caused by the invading pathogens such as 'Candidatus Liberibacter asiaticus' (Bové 2006; Wang 2019) on the citrus-associated microbiome (Table 2). These reports demonstrated restructuring of overall community composition in the leaves (Araújo et al. 2002; Blaustein et al. 2017; Ginnan et al. 2020; Sagaram et al. 2009), stem (Ginnan et al. 2020), roots (Blaustein et al. 2017; Ginnan et al. 2020; Padhi et al. 2019; Trivedi et al. 2010), rhizoplane (Zhang et al. 2017), and rhizosphere (Trivedi et al. 2012; Zhang et al. 2017) of citrus microbiome. In general, $\alpha$ diversity decreases as a result of ' $\mathrm{Ca}$. L. asiaticus' colonization and huanglongbing (HLB) disease progression (Blaustein et al. 2017; Trivedi et al. 2012). Araújo et al. (2002) reported significant changes in the endophytic microbial community in response to citrus variegated chlorosis (CVC) caused by the bacterium Xylella fastidiosa. Infection of citrus roots by the fibrous rootfeeding nematode Tylenchulus semipenetrans induces shifts in the rhizosphere microbiome leading to the increased abundance of Bacillus megaterium and Burkholderia cepacia (El-Borai et al. 2003). The enrichment of these bacterial species had a negative effect on the growth of the root rot pathogen Phytophthora nicotianae (El-Borai et al. 2003). HLB alters the rhizosphere microbial community from being primarily "copiotrophic" (fast growing, utilizing labile C source and dominant in the rhizosphere) to "oligotrophic" (slow growing, utilizing recalcitrant $\mathrm{C}$ source and dominant in the bulk soil) (Trivedi et al. 2012). Changes in the rhizosphere microbial community and further rhizosphere-to-rhizoplane enrichment behavior in response to HLB suggests that the "rhizosphere effect" responsible for the selective recruitment of microbes from bulk soil is negatively affected by HLB disease (Trivedi et al. 2012; Zhang et al. 2017). These observations indicate that the pathogen exposure (' $\mathrm{Ca}$. L. asiaticus' being an obligate endophytic bacterium) can restructure the native microbial community even when the direct competition effect is lacking. The restructuring of the microbial community in this case is postulated to be driven by the alterations in plant physiology leading to quantitative and qualitative changes in partitioning of photoassimilates in the rhizosphere.

A disease ecology model that illustrates the relationship between pathogen, enrichments or depletions of microbial populations within the microbiome, and the host plant has been proposed (Table 2). This model predicts the role of members of the native citrus microbial community as disease facilitators or suppressors and has generated many testable hypotheses stemming from DNA-based methods if studying the citrus microbiome (Ginnan et al. 2020). In addition, cooccurrence patterns determined by network analysis of HLBinfected leaf samples demonstrates negative interactions between ' $\mathrm{Ca}$. L. asiaticus' and a few native bacteria belonging to the core microbiota of citrus (Blaustein et al. 2017). Few studies have shown a positive correlation between ' $\mathrm{Ca}$. L. asiaticus' abundance and a few bacterial phylotypes in the root (Ginnan et al. 2020; Trivedi et al. 2010) and leaf (Blaustein et al. 2017; Sagaram et al. 2009). Fujiwara et al. (2018) demonstrated that the survival of ' $\mathrm{Ca}$. L. asiaticus' depends on the interplay with a specific subset of citrus-associated microbiota dominated by members of the families Comamonadaceae, Flavobacterium, Microbacteriaceae, and Pseudomonadaceae. The antibiotic application that eliminated the specific subset significantly reduced ' $\mathrm{Ca}$. L. asiaticus' abundance (Table 2). In the CVC pathosystem, there is a relationship between CVC symptoms and the frequency of isolation of Methylobacterium spp. (Araújo et al. 2002). The in vitro interaction experiments indicated that the growth of $X$. fastidiosa

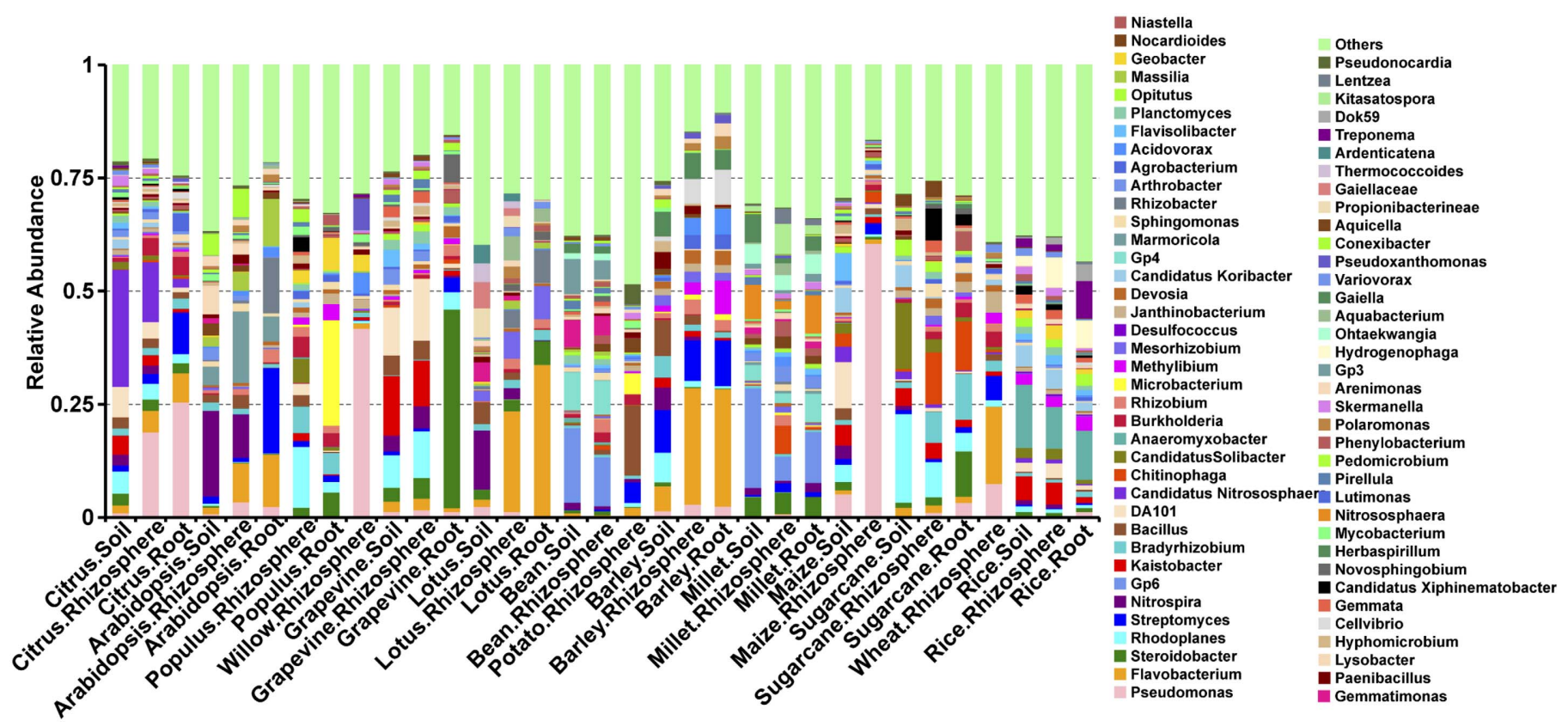

Fig. 5. Taxonomic distribution of plant root-associated microbiomes of 15 plant species at the genus level identified using the $16 \mathrm{~S}$ data. Data were derived from public data sets (Bulgarelli et al. 2012, 2015; Cúcio et al. 2016; de Souza et al. 2016; Donn et al. 2015; Edwards et al. 2015; Gottel et al. 2011; Jin et al. 2017; Pérez-Jaramillo et al. 2017; Pfeiffer et al. 2017; Xu et al. 2018; Yergeau et al. 2015; Zarraonaindia et al. 2015; Zgadzaj et al. 2016). 
was stimulated by endophytic Methylobacterium extorquens (Lacava et al. 2004). These data suggest that incoming pathogens interact with the native microbial community for colonization and construction of a pathogen-associated community that could stimulate disease development. Although not fully understood, the possible mechanisms in the interactions between resident microbes and pathogens may involve microbial cross-talk, effect on the plant hosts, competition for nutrients and space, production of metabolites, change in niche environment, or acting collectively with selected native microbes to form a stable consortium resulting in mutual benefits for the members of the community (Trivedi et al. 2016).

Tree decline associated with HLB disease is proposed to be not solely attributed to the increasing abundance of the ' $\mathrm{Ca}$. L. asiaticus' pathogen but also as a result of the native microbial community shifting from enrichments by mutualistic or symbiotic to pathogenic or saprophytic microorganisms, particularly in the root compartment (Ginnan et al. 2020) (Table 2). As disease severity increased, HLBaffected root samples had a significantly reduced relative abundance of fungal phylum Glomeromycota (Ginnan et al. 2020), which contains many species of symbiotic mycorrhizal fungi that provide critical benefits to plants, including nutrient uptake and stress tolerance (Begum et al. 2019). The decrease in the relative abundance of beneficial species of Glomeromycota coincided with significant increases in the fungal genera Fusarium and Gibberella in roots of HLBdiseased citrus (Ginnan et al. 2020). Members of both Fusarium and Gibberella are known to cause plant diseases, including citrus dry root rot caused by Fusarium oxysporum (Yaseen and D'Onghia
2012). In addition, Phytophthora incidence increased when trees became infected with HLB (Ginnan et al. 2020). Graham et al. (2013) reported potential interactions of HLB and Phytophthora spp. in causing presymptomatic fibrous root decline in citrus. Suppressing plant defense responses by incoming pathogens provides opportunities for native saprophytes or pathogens to colonize different plant niches. Li et al. (2017) showed that, by degrading salicylic acid, ' $\mathrm{Ca}$. L. asiaticus' enhances the susceptibility of citrus plants to both nonpathogenic and pathogenic strains of Xanthomonas citri. Disease progression can cause dysbiosis in the plant-associated microbiome by negatively affecting the relative abundances of keystone species that are postulated to stabilize microbial communities (Agler et al. 2016). Loss of keystone species due to ' $\mathrm{Ca}$. L. asiaticus' infection has been reported to trigger cascade processes that destabilize the structure of the citrus-associated microbiome (Ginnan et al. 2020).

The effect of disease on the citrus microbiome is affected by various factors, including location, rootstock, scion, tree age, time of sampling, symptoms, and disease tolerance (Blaustein et al. 2017; Ginnan et al. 2020) (Table 2). Variations in the citrusassociated microbiome due to HLB progression has led to the identification of microbial signatures associated with early and late phases of the disease (Ginnan et al. 2020). For example, the populations of Exophiala sp. and Lactobacillus spp. in roots and Aureobasidium sp. and Methylobacterium spp. in leaves were significantly enriched in the early to moderate stages of HLB progression but significantly dropped in highly symptomatic trees. On the other hand, the populations of Camptophora sp. and

TABLE 2

Summary of disease effect on citrus microbiome

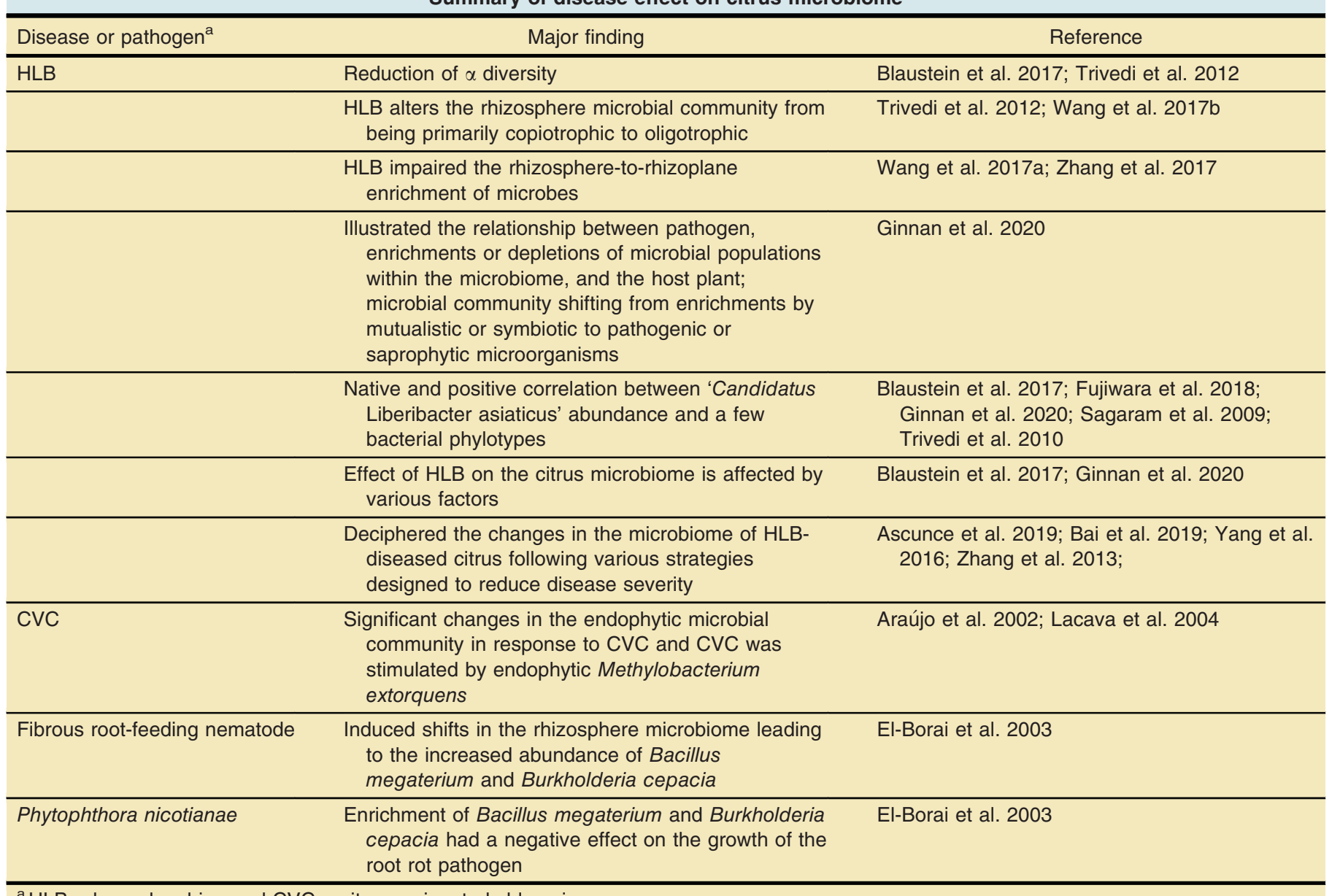

${ }^{\mathrm{a}} \mathrm{HLB}=$ huanglongbing and $\mathrm{CVC}=$ citrus variegated chlorosis. 
Acrodontium sp. found in leaves were significantly higher in severely diseased trees than moderately diseased trees. A few studies have also deciphered the changes in the microbiome of HLB-diseased citrus following various strategies designed to reduce disease severity (Bai et al. 2019; Yang et al. 2016; Zhang et al. 2013). Although changes in the microbial community composition fluctuated due to the application of biofertilizers (Bai et al. 2019), antibiotic application (Ascunce et al. 2019; Hu and Wang 2016; Li et al. 2019b; Yang et al. 2016; Zhang et al. 2013), and thermotherapy (Li et al. 2019a; Yang et al. 2016), it is difficult to infer whether the community returned back to its original composition or shifted further to an alternate composition.

A few studies have examined the effects of plant pathogens on the structure of plant-associated bacterial communities (discussed above); however, we have a limited understanding of the functional features of a plant-associated microbiome assembled in response to disease progression. We also have a minimal understanding of the implications of these shifts on ecosystem-level functions and plant-microbiome interactions. Using shotgun metagenomics and metatranscriptomics approaches, Zhang et al. (2017) demonstrated that HLB impairs the rhizosphere-to-rhizoplane enrichment process of the citrus root-associated microbiome. The two most dominant rhizosphere enriched genera, Bradyrhizobium and Burkholderia, were significantly decreased in the HLB-infected rhizoplane. Many genes related to functional traits under selective pressure for the recruitment of the rhizosphere microbiome, including genes related to motility, chemotaxis, secretion systems, and quorum sensing, were significantly reduced due to HLB (Zhang et al. 2017). Using GeoChip analysis, Trivedi et al. (2012) showed that there was a significant decrease in various genes involved in $\mathrm{N}$ and $\mathrm{P}$ cycling in the rhizosphere microbiome of HLB-diseased citrus trees compared with that of healthy ones (Trivedi et al. 2012). Because the diversity and stability of plant-associated microbial communities heavily influence soil quality, plant production, and ecosystem processes, fluctuations in the microbial community structure and functions could have severe implications in ecosystem sustainability.

\section{POTENTIAL AND APPLICATION OF MANIPULATION OR ENGINEERING CITRUS MICROBIOME}

The emerging "cry for help" hypothesis postulates that plants recruit specific microbes that are able to alleviate plant stress in a given situation (López-Ráez et al. 2011; Neal et al. 2012; Rudrappa et al. 2008). There is also evidence to suggest that plants recruit specific beneficial microbes to promote plant immunity. Harnessing the largely unexplored functional potential of the plant-associated microbiome has tremendous potential to expand the genomic capabilities of their host by improving nutrient uptake, enhancing tolerance to environmental stress, and providing protection against pests and diseases. In this context, microbiome engineering has recently emerged as an alternative to promote positive plant-microbiome interactions in order to improve plant fitness (Mueller and Sachs 2015; Qiu et al. 2019; Sessitsch and Mitter 2015; Timmusk et al. 2017; Trivedi et al. 2016). The microbiome engineering approach presents a safer alternative with respect to environmental safety and even public health (e.g., avoid antibiotics contamination and ARG dissemination) compared with the aforementioned antibiotics treatments.

Some indications of the "cry for help" hypothesis has been found in citrus where early stages of disease development resulted in the increased abundance of certain microbial groups that are reported to possess plant growth promotion traits (Blaustein et al. 2017; Ginnan et al. 2020). Systemic investigations of disease escape trees (i.e., healthy-looking trees in citrus groves with high disease incidence) have resulted in the identification, isolation, and characterization of microbes with potential for plant growth promotion and biocontrol (Araújo et al. 2002; Lacava et al. 2004; Riera et al. 2017; Trivedi et al. 2010). These "escape" citrus trees share the same genotype as symptomatic trees and are grown under similar environmental conditions. Therefore, it has been proposed that the escape trees differ in their disease tolerance because of their associated microbial community composition (Araújo et al. 2002; Sagaram et al. 2009; Trivedi et al. 2016). The microbial community of the escape plant was enriched in microbes with multiple beneficial traits (i.e., $\mathrm{N}$ fixation, $\mathrm{P}$ solubilization, production of phytohormones, and stressrelieving enzymes) compared with those of symptomatic trees (Trivedi et al. 2010). Other studies have also isolated and characterized citrus-associated microbes for beneficial properties, including antagonistic activities against citrus pathogens (Araújo et al. 2002; Blacutt et al. 2020; Lacava et al. 2004; Riera et al. 2017), with a broad aim to manipulate the microbiome primarily through the application of bioinoculants consisting of single or a combination of beneficial strains. Recently, Blacutt et al. (2020) developed a high-throughput culturing and taxonomic identification pipeline to build a repository of citrus-associated microorganisms that reside in the HLB disease environment. The repository was further screened for potential anti- ' $C a$. L. asiaticus' bioinoculants. A few of the bacterial strains have been sequenced to provide better understanding on the genomic features of beneficial traits and plant colonization abilities (Riera et al. 2017; Zhang et al. 2017).

In planta assays using greenhouse trials have revealed the positive effects on citrus growth and performance by inoculation of beneficial strains (Azevedo et al. 2016; Giassi et al. 2016; Lacava et al. 2007; Riera et al. 2018). Root application of three rhizobacterial strains reduced canker symptoms caused by the bacterium $X$. citri pv. citri by inducing systemic immune response in grapefruit (Riera et al. 2018). Inoculation of periwinkle with Curtobacterium flaccumfaciens decreased population levels of Xylella fastidiosa, resulting in reduced CVC symptoms (Lacava et al. 2007). Giassi et al. (2016) showed that some isolates were able to promote growth of citrus rootstocks; however, the response was dependent on the genotype and microbial isolate. Inoculation of citrus rootstocks with mycorrhizal fungi enhances drought tolerance (Liu et al. 2018, 2019; Zhang et al. 2019; Zou et al. 2017). Zhang et al. (2019) demonstrated that common mycorrhizal networks can transfer the salicylic acid signal from infected to neighboring healthy seedlings, resulting in defense response activation in the neighboring plants. In spite of showing remarkable efficacy to influence plant growth promotion in greenhouse trials, the in-field success of microbial inoculation remains unpredictable and unreliable. This is likely due to the inability of microbial bioinoculants to effectively compete with the native microflora and colonize plant-associated environments to manifest their beneficial traits (Kaminsky et al. 2019; Trivedi et al. 2020). Furthermore, it is important to consider the dynamic nature of the microbiome and characteristics of the pathogens to apply the beneficial microbes to specific locations and times to maximize the beneficial effect (Sundin et al. 2016). For example, treatment of immature leaves, which are more susceptible to Xanthomonas citri infection, with beneficial bacteria has shown promising effect against citrus canker, probably by occupying the space underneath stomata and their antimicrobial activities or inducing plant defense (J. Li and N. Wang, unpublished data).

In recent years, significant progress has been made in understating the makeup and functional potential of plant-associated microbiomes (Leach et al. 2017; Trivedi et al. 2020; Xu et al. 2018). Because microbiome engineering has been identified as a major route to increase plant resistance to biotic or abiotic stress, interest and investment in developing microbial inoculants to 
enhance these functions has recently surged (Kaminsky et al. 2019). To effectively harness the microbiome requires new approaches which recognize that microbes living in natural and managed systems typically do so as communities-not as populations of single organisms functioning alone (de Vries and Wallenstein 2017; Vannier et al. 2019; Woo and Pepe 2018). Fundamental ecological and design principles underpinning complex microbial communities are in their infancy but are critical to the rational design and manipulation of microbiomes in agricultural systems (Mitter et al. 2017; Sessitsch et al. 2019; Vannier et al. 2019; Vorholt et al. 2017). Advancement in modeling and data visualization techniques allows us to identify keystone microbes that orchestrate variations in the microbiome structure and function (Agler et al. 2016). New highthroughput culturing approaches can be used to selectively isolate keystone microbes that are driving key microbial interactions related to plant performance. For example, using network analysis Blaustein et al. (2017) identified several microbial groups that showed negative correlation with ' $\mathrm{Ca}$. L. asiaticus'. These native microbes may represent prime targets for the development of microbial inoculants to control HLB. Of note, observation to application is not a simple and direct process and extensive efforts are needed for identifying applicable inoculants from these candidate microbial groups, in that individuals affiliated with the same taxon in the microbiome would exhibit distinct abilities on pathogen antagonism and plant colonization (Mauchline and Malone 2017) and, thus, a relatively large population of the targeted microbes should be isolated and evaluated to obtain the isolates suitable for field application.
We envision that detailed understanding of plant-microbiome interactions will allow us to rationally design microbial consortia with broad, durable, and flexible plant-growth-promoting activities in natural environments. New and emerging strategies to improve the survival and activity of microbial inoculants, including using selected indigenous microbes and optimizing microbial delivery methods, as well as modern gene editing tools (RNAi, CRISPR/Cas9, and so on) to engineer microbial inoculants will provide a way forward for in situ microbiome engineering (Qiu et al. 2019). Identification and application of antimicrobial compounds that can specifically target the pathogens but not kill the beneficial microbes in the microbiome is another potential effective means to control the disease (Gardner et al. 2020). Demonstration of the efficacy of microbial product in field conditions will further guide large-scale adoption of innovative microbiome technologies to combat plant diseases and stress tolerance under a range of environmental contexts. In addition to the development of optimized microbial inoculants we also envision direct manipulation of the microbiome using designer plants that express microbial circuits involved in signal exchange that can manipulate the microbiome for desired benefits (Qiu et al. 2019; Trivedi et al. 2017). For example, synthetic biology approaches have been developed to engineer transkingdom signaling in plants to control gene expression in rhizosphere bacteria (Geddes et al. 2019). In addition, it was reported that terrestrial plants control the level and nurture the diversity of endophytic phyllosphere microbiota via a genetic network to prevent dysbiosis (Chen et al. 2020). Thus, it is possible to manipulate the microbiome by genome editing of the hosts with

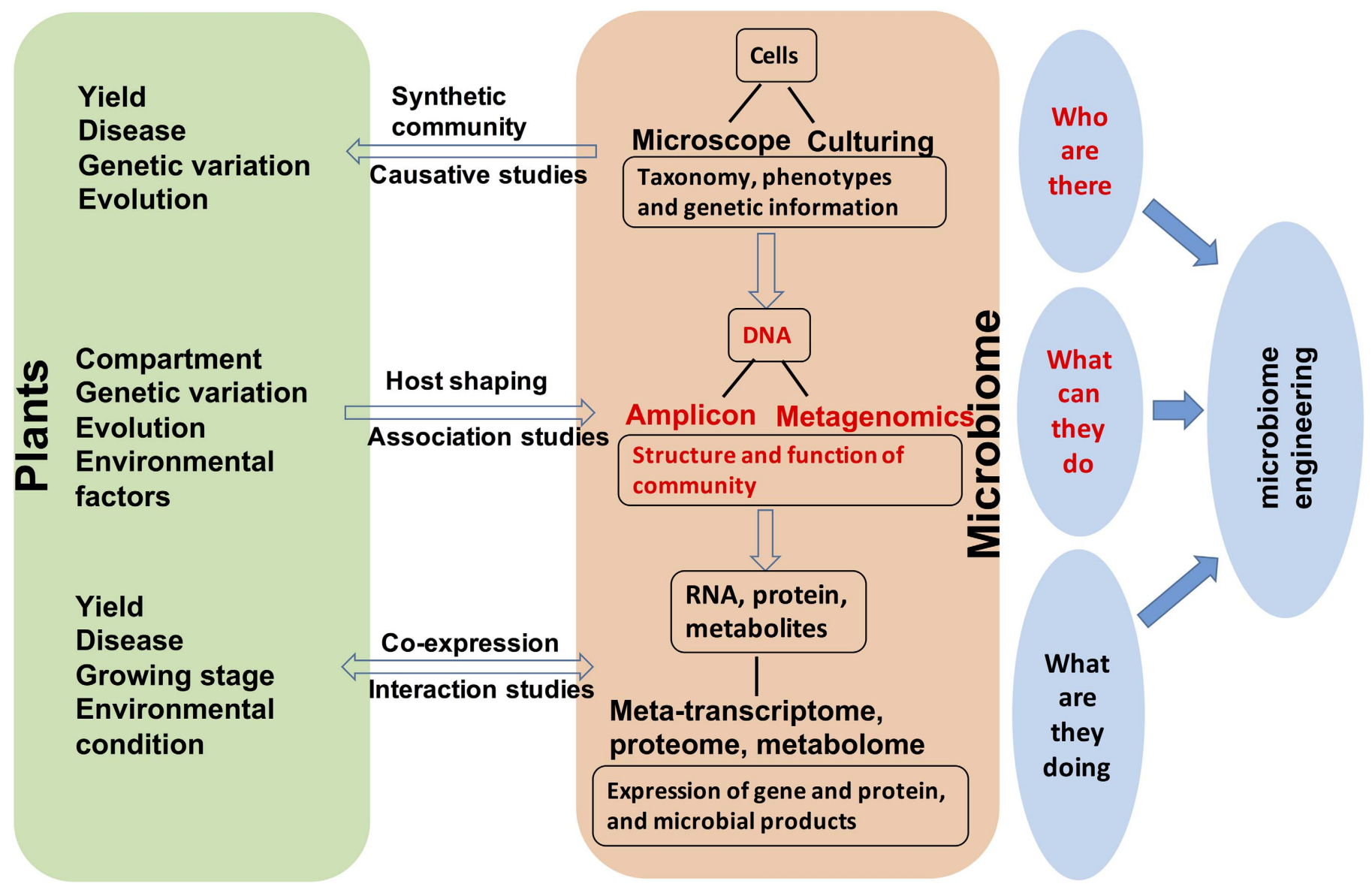

Fig. 6. Proposed methods and questions for citrus microbiome studies. Red color highlights the current progress of understanding the citrus microbiome. 
the rapid development of the CRISPR technology and its application on citrus (Barrangou and Doudna 2016; Cong et al. 2013; Huang et al. 2020; Jia and Wang 2020, 2014a, b; Jia et al. 2017a, b, 2019; Jinek et al. 2012; LeBlanc et al. 2017). These advances will open up approaches to rewire plant-microbiome interactions to activate specific members of microbiota to fix $\mathrm{N}_{2}$, produce antibiotics or hormones, chelate iron, or solubilize soil nutrients. These upcoming tools and technologies that allow us to engineer plant-associated microbiome are urgently needed to save citrus from the HLB crisis.

\section{PERSPECTIVE}

Overall, previous studies have provided valuable knowledge of the citrus microbiome, including taxonomic composition and functional potential across compartments, locations, and different disease conditions. However, utilization of the citrus microbiome remains in its infancy. In the long run, to improve citrus production and health via microbiome engineering, we need to attain a systems-level understanding of citrus microbiome (Fig. 6). We envision that the broad application of multiomics methods, network analysis, consortia of microbes, artificial intelligence, genome editing, and high-throughput culturing will significantly advance our understanding of citrus microbiome and further liberate the potentials of the citrus microbiome (Fig. 6).

\section{LITERATURE CITED}

Agler, M. T., Ruhe, J., Kroll, S., Morhenn, C., Kim, S. T., Weigel, D., and Kemen, E. M. 2016. Microbial hub taxa link host and abiotic factors to plant microbiome variation. PLoS Biol. 14:e1002352.

An, S. Q., Potnis, N., Dow, M., Vorhölter, F. J., He, Y. Q., Becker, A., Teper, D., Li, Y., Wang, N., Bleris, L., and Tang, J. L. 2020. Mechanistic insights into host adaptation, virulence and epidemiology of the phytopathogen Xanthomonas. FEMS Microbiol. Rev. 44:1-32.

Araújo, W. L., Marcon, J., Maccheroni, W., van Elsas, J. D., van Vuurde, J. W. L., and Azevedo, J. L. 2002. Diversity of endophytic bacterial populations and their interaction with Xylella fastidiosa in citrus plants. Appl. Environ. Microbiol. 68:4906-4914.

Ascunce, M. S., Shin, K., Huguet-Tapia, J. C., Poudel, R., Garrett, K. A., van Bruggen, A. H. C., and Goss, E. M. 2019. Penicillin trunk injection affects bacterial community structure in citrus trees. Microb. Ecol. 78:457-469.

Azevedo, J. L., Araújo, W. L., and Lacava, P. T. 2016. The diversity of citrus endophytic bacteria and their interactions with Xylella fastidiosa and host plants. Genet. Mol. Biol. 39:476-491.

Bai, Y. N., Wang, J. C., Jin, L., Zhan, Z. G., Guan, L. M., Zheng, G. H., Qiu, D. W., and Qiu, X. Z. 2019. Deciphering bacterial community variation during soil and leaf treatments with biologicals and biofertilizers to control huanglongbing in citrus trees. J. Phytopathol. 167:686-694.

Bais, H. P., Weir, T. L., Perry, L. G., Gilroy, S., and Vivanco, J. M. 2006. The role of root exudates in rhizosphere interactions with plants and other organisms. Annu. Rev. Plant Biol. 57:233-266.

Barrangou, R., and Doudna, J. A. 2016. Applications of CRISPR technologies in research and beyond. Nat. Biotechnol. 34:933-941.

Begum, N., Qin, C., Ahanger, M. A., Raza, S., Khan, M. I., Ashraf, M., Ahmed, N., and Zhang, L. X. 2019. Role of arbuscular mycorrhizal fungi in plant growth regulation: Implications in abiotic stress tolerance. Front. Plant Sci. 10:1068.

Berendsen, R. L., Pieterse, C. M., and Bakker, P. A. 2012. The rhizosphere microbiome and plant health. Trends Plant Sci. 17:478-486.

Berg, G., Rybakova, D., Grube, M., and Koberl, M. 2016. The plant microbiome explored: Implications for experimental botany. J. Exp. Bot. 67:995-1002.

Blacutt, A., Ginnan, N., Dang, T., Bodaghi, S., Vidalakis, G., Ruegger, P., Peacock, B., Viravathana, P., Vieira, F. C., Drozd, C., Jablonska, B., Borneman, J., McCollum, G., Cordoza, J., Meloch, J., Berry, V., Salazar, L. L., Maloney, K. N., Rolshausen, P. E., and Roper, M. C. 2020. An in vitro pipeline for screening and selection of citrus-associated microbiota with potential anti-"Candidatus Liberibacter asiaticus" properties. Appl. Environ. Microbiol. 86:e02883-19.
Blaustein, R. A., Lorca, G. L., Meyer, J. L., Gonzalez, C. F., and Teplitski, M. 2017. Defining the core citrus leaf- and root-associated microbiota: Factors associated with community structure and implications for managing huanglongbing (citrus greening) disease. Appl. Environ. Microbiol. 83:e0210-17.

Bové, J. M. 2006. Huanglongbing: A destructive, newly-emerging, centuryold disease of citrus. J. Plant Pathol. 88:7-37.

Bulgarelli, D., Garrido-Oter, R., Munch, P. C., Weiman, A., Droge, J., Pan, Y., McHardy, A. C., and Schulze-Lefert, P. 2015. Structure and function of the bacterial root microbiota in wild and domesticated barley. Cell Host Microbe 17:392-403.

Bulgarelli, D., Rott, M., Schlaeppi, K., Ver Loren van Themaat, E., Ahmadinejad, N., Assenza, F., Rauf, P., Huettel, B., Reinhardt, R., Schmelzer, E., Peplies, J., Gloeckner, F. O., Amann, R., Eickhorst, T., and Schulze-Lefert, P. 2012. Revealing structure and assembly cues for Arabidopsis root-inhabiting bacterial microbiota. Nature 488:91-95.

Bulgarelli, D., Schlaeppi, K., Spaepen, S., Ver Loren van Themaat, E., and Schulze-Lefert, P. 2013. Structure and functions of the bacterial microbiota of plants. Annu. Rev. Plant Biol. 64:807-838.

Campos-Herrera, R., Pathak, E., El-Borai, F. E., Stuart, R. J., Gutierrez, C., Rodriguez-Martin, J. A., Graham, J. H., and Duncan, L. W. 2013. Geospatial patterns of soil properties and the biological control potential of entomopathogenic nematodes in Florida citrus groves. Soil Biol. Biochem. 66:163-174.

Carlström, C. I., Field, C. M., Bortfeld-Miller, M., Müller, B., Sunagawa, S., and Vorholt, J. A. 2019. Synthetic microbiota reveal priority effects and keystone strains in the Arabidopsis phyllosphere. Nat. Ecol. Evol. 3:1445-1454.

Chen, T., Nomura, K., Wang, X., Sohrabi, R., Xu, J., Yao, L., Paasch, B. C., Ma, L., Kremer, J., Cheng, Y., Zhang, L., Wang, N., Wang, E., Xin, X.F., and He, S. Y. 2020. A plant genetic network for preventing dysbiosis in the phyllosphere. Nature 580:653-657.

Cole, B. J., Feltcher, M. E., Waters, R. J., Wetmore, K. M., Mucyn, T. S., Ryan, E. M., Wang, G. Y., Ul-Hasan, S., McDonald, M., Yoshikuni, Y., Malmstrom, R. R., Deutschbauer, A. M., Dang, J. L., and Visel, A. 2017. Genome-wide identification of bacterial plant colonization genes. PLoS Biol. 15:e2002860.

Cong, L., Ran, F. A., Cox, D., Lin, S., Barretto, R., Habib, N., Hsu, P. D., Wu, X., Jiang, W., Marraffini, L. A., and Zhang, F. 2013. Multiplex genome engineering using CRISPR/Cas systems. Science 339:819-823.

Cúcio, C., Engelen, A. H., Costa, R., and Muyzer, G. 2016. Rhizosphere microbiomes of European seagrasses are selected by the plant, but are not species specific. Front. Microbiol. 7:440.

Cui, Z., Huntley, R. B., Zeng, Q., and Steven, B. 2021. Temporal and spatial dynamics in the apple flower microbiome in the presence of the phytopathogen Erwinia amylovora. ISME J. 15:318-329.

de Souza, R. S., Okura, V. K., Armanhi, J. S. L., Jorrín, B., Lozano, N., da Silva, M. J., González-Guerrero, M., de Araújo, L. M., Verza, N. C., Bagheri, H. C., Imperial, J., and Arruda, P. 2016. Unlocking the bacterial and fungal communities assemblages of sugarcane microbiome. Sci. Rep. 6:28774.

de Vries, F. T., and Wallenstein, M. D. 2017. Below-ground connections underlying above-ground food production: A framework for optimising ecological connections in the rhizosphere. J. Ecol. 105:913-920.

Donn, S., Kirkegaard, J. A., Perera, G., Richardson, A. E., and Watt, M. 2015. Evolution of bacterial communities in the wheat crop rhizosphere. Environ. Microbiol. 17:610-621.

Edwards, J., Johnson, C., Santos-Medellin, C., Lurie, E., Podishetty, N. K., Bhatnagar, S., Eisen, J. A., and Sundaresan, V. 2015. Structure, variation, and assembly of the root-associated microbiomes of rice. Proc. Natl. Acad. Sci. U.S.A. 112:E911-E920.

Eisvand, P., Farrokhi Nejad, R., and Azimi, S. 2019. Plant parasitic nematodes fauna in citrus orchards in Khuzestan province, Southwestern Iran. Hell. Plant Prot. J. 12:97-107.

El-Borai, F. E., Duncan, L. W., Graham, J. H., and Dickstein, E. 2003. Tylenchulus semipenetrans alters the microbial community in the citrus rhizosphere. J. Nematol. 35:167-177.

Ference, C. M., Gochez, A. M., Behlau, F., Wang, N., Graham, J. H., and Jones, J. B. 2018. Recent advances in the understanding of Xanthomonas citri ssp. citri pathogenesis and citrus canker disease management. Mol. Plant Pathol. 19:1302-1318.

Fravel, D., Olivain, C., and Alabouvette, C. 2003. Fusarium oxysporum and its biocontrol. New Phytol. 157:493-502.

Fujiwara, K., Iwanami, T., and Fujikawa, T. 2018. Alterations of Candidatus Liberibacter asiaticus-associated microbiota decrease survival of $\mathrm{Ca}$. L. asiaticus in in vitro assays. Front. Microbiol. 9:3089. 
Gardner, C. L., da Silva, D. R., Pagliai, F. A., Pan, L., Padgett-Pagliai, K. A., Blaustein, R. A., Merli, M. L., Zhang, D., Pereira, C., Teplitski, M., Chaparro, J. X., Folimonova, S. Y., Conesa, A., Gezan, S., Lorca, G. L., and Gonzalez, C. F. 2020. Assessment of unconventional antimicrobial compounds for the control of 'Candidatus Liberibacter asiaticus', the causative agent of citrus greening disease. Sci. Rep. 10:5395.

Geddes, B. A., Paramasivan, P., Joffrin, A., Thompson, A. L., Christensen, K., Jorrin, B., Brett, P., Conway, S. J., Oldroyd, G. E. D., and Poole, P. S. 2019. Engineering transkingdom signalling in plants to control gene expression in rhizosphere bacteria. Nat. Commun. 10:3430.

Geisen, S., Koller, R., Hünninghaus, M., Dumack, K., Urich, T., and Bonkowski, M. 2016. The soil food web revisited: Diverse and widespread mycophagous soil protists. Soil Biol. Biochem. 94:10-18.

Giassi, V., Kiritani, C., and Kupper, K. C. 2016. Bacteria as growthpromoting agents for citrus rootstocks. Microbiol. Res. 190:46-54.

Ginnan, N. A., Dang, T., Bodaghi, S., Ruegger, P. M., McCollum, G., England, G., Vidalakis, G., Borneman, J., Rolshausen, P. E., and Roper, M. C. 2020. Disease-induced microbial shifts in citrus indicate microbiome-derived responses to huanglongbing across the disease severity spectrum. Phytobiomes J. 4:375-387.

Goh, K. M., Shahar, S., Chan, K. G., Chong, C. S., Amran, S. I., Sani, M. H., Zakaria, I. I., and Kahar, U. M. 2019. Current status and potential applications of underexplored prokaryotes. Microorganisms 7:468.

Gottel, N. R., Castro, H. F., Kerley, M., Yang, Z. M., Pelletier, D. A., Podar, M., Karpinets, T., Uberbacher, E., Tuskan, G. A., Vilgalys, R., Doktycz, M. J., and Schadt, C. W. 2011. Distinct microbial communities within the endosphere and rhizosphere of Populus deltoides roots across contrasting soil types. Appl. Environ. Microbiol. 77:5934-5944.

Graham, J. H., Johnson, E. G., Gottwald, T. R., and Irey, M. S. 2013. Presymptomatic fibrous root decline in citrus trees caused by huanglongbing and potential interaction with Phytophthora spp. Plant Dis. 97:1195-1199.

Hacquard, S., Garrido-Oter, R., González, A., Spaepen, S., Ackermann, G., Lebeis, S., McHardy, A. C., Dangl, J. L., Knight, R., Ley, R., and Schulze-Lefert, P. 2015. Microbiota and host nutrition across plant and animal kingdoms. Cell Host Microbe 17:603-616.

Hacquard, S., Spaepen, S., Garrido-Oter, R., and Schulze-Lefert, P. 2017. Interplay between innate immunity and the plant microbiota. Annu. Rev. Phytopathol. 55:565-589.

Hamonts, K., Trivedi, P., Garg, A., Janitz, C., Grinyer, J., Holford, P., Botha, F. C., Anderson, I. C., and Singh, B. K. 2018. Field study reveals core plant microbiota and relative importance of their drivers. Environ. Microbiol. 20:124-140.

Haney, C. H., Samuel, B. S., Bush, J., and Ausubel, F. M. 2015. Associations with rhizosphere bacteria can confer an adaptive advantage to plants. Nat. Plants 1:15051

Heravi, F. S., Zakrzewski, M., Vickery, K., and Hu, H. 2020. Host DNA depletion efficiency of microbiome DNA enrichment methods in infected tissue samples. J. Microbiol. Methods 170:105856.

Herrera Paredes, S., and Lebeis, S. L. 2016. Giving back to the community: Microbial mechanisms of plant-soil interactions. Funct. Ecol. 30:1043-1052.

Hu, J., and Wang, N. 2016. Evaluation of the spatiotemporal dynamics of oxytetracycline and its control effect against citrus Huanglongbing via trunk injection. Phytopathology 106:1495-1503.

Hu, L. F., Robert, C. A. M., Cadot, S., Zhang, X., Ye, M., Li, B. B., Manzo, D., Chervet, N., Steinger, T., van der Heijden, M. G. A., Schlaeppi, K., and Erb, M. 2018. Root exudate metabolites drive plant-soil feedbacks on growth and defense by shaping the rhizosphere microbiota. Nat. Commun. 9:2738.

Huang, X., Wang, Y., Xu, J., and Wang, N. 2020. Development of multiplex genome editing toolkits for citrus with high efficacy in biallelic and homozygous mutations. Plant Mol. Biol. 104:297-307.

Jia, H., Orbović, V., and Wang, N. 2019. CRISPR-LbCas12a-mediated modification of citrus. Plant Biotechnol. J. 17:1928-1937.

Jia, H., and Wang, N. 2014a. Xcc-facilitated agroinfiltration of citrus leaves: A tool for rapid functional analysis of transgenes in citrus leaves. Plant Cell Rep. 33:1993-2001.

Jia, H., and Wang, N. 2014b. Targeted genome editing of sweet orange using Cas9/sgRNA. PLoS One 9:e93806.

Jia, H., and Wang, N. 2020. Generation of homozygous canker-resistant citrus in the T0 generation using CRISPR-SpCas9p. Plant Biotechnol. J. 18: 1990-1992.

Jia, H., Xu, J., Orbović, V., Zhang, Y., and Wang, N. 2017a. Editing citrus genome via SaCas9/sgRNA system. Front. Plant Sci. 8:2135.
Jia, H., Zhang, Y., Orbović, V., Xu, J., White, F. F., Jones, J. B., and Wang, N. 2017b. Genome editing of the disease susceptibility gene CsLOB1 in citrus confers resistance to citrus canker. Plant Biotechnol. J. 15:817-823.

Jin, T., Wang, Y. Y., Huang, Y. Y., Xu, J., Zhang, P. F., Wang, N., Liu, X., Chu, H. Y., Liu, G., Jiang, H. G., Li, Y. Z., Xu, J., Kristiansen, K., Xiao, L., Zhang, Y. Z., Zhang, G. Y., Du, G. H., Zhang, H. B., Zou, H. F., Zhang, H. F., Jie, Z. Y., Liang, S. S., Jia, H. J., Wan, J. W., Lin, D. C., Li, J. Y., Fan, G. Y., Yang, H. M., Wang, J., Bai, Y., and Xu, X. 2017. Taxonomic structure and functional association of foxtail millet root microbiome. Gigascience 6:1-12.

Jinek, M., Chylinski, K., Fonfara, I., Hauer, M., Doudna, J. A., and Charpentier, E. 2012. A programmable dual-RNA-guided DNA endonuclease in adaptive bacterial immunity. Science 337:816-821.

Kaminsky, L. M., Trexler, R. V., Malik, R. J., Hockett, K. L., and Bell, T. H. 2019. The inherent conflicts in developing soil microbial inoculants. Trends Biotechnol. 37:140-151.

Koczan, J. M., Lenneman, B. R., McGrath, M. J., and Sundin, G. W. 2011. Cell surface attachment structures contribute to biofilm formation and xylem colonization by Erwinia amylovora. Appl. Environ. Microbiol. 77:7031-7039.

Kwak, M. J., Kong, H. G., Choi, K., Kwon, S. K., Song, J. Y., Lee, J., Lee, P. A., Choi, S. Y., Seo, M., Lee, H. J., Jung, E. J., Park, H., Roy, N., Kim, H., Lee, M. M., Rubin, E. M., Lee, S. W., and Kim, J. F. 2018. Rhizosphere microbiome structure alters to enable wilt resistance in tomato. Nat. Biotechnol. 36:1100-1109.

Lacava, P. T., Araújo, W. L., Marcon, J., Maccheroni, W., and Azevedo, J. L. 2004. Interaction between endophytic bacteria from citrus plants and the phytopathogenic bacteria Xylella fastidiosa, causal agent of citrusvariegated chlorosis. Lett. Appl. Microbiol. 39:55-59.

Lacava, P. T., Li, W., Araújo, W. L., Azevedo, J. L., and Hartung, J. S. 2007. The endophyte Curtobacterium flaccumfaciens reduces symptoms caused by Xylella fastidiosa in Catharanthus roseus. J. Microbiol. 45:388-393.

Lareen, A., Burton, F., and Schafer, P. 2016. Plant root-microbe communication in shaping root microbiomes. Plant Mol. Biol. 90:575-587.

Leach, J. E., Triplett, L. R., Argueso, C. T., and Trivedi, P. 2017. Communication in the phytobiome. Cell 169:587-596.

LeBlanc, C., Zhang, F., Mendez, J., Lozano, Y., Chatpar, K., Irish, V., and Jacob, Y. 2017. Increased efficiency of targeted mutagenesis by CRISPR/ Cas9 in plants using heat stress. Plant J. 93:377-386.

Lemanceau, P., Blouin, M., Müller, D., and Moenne-Loccoz, Y. 2017. Let the core microbiota be functional. Trends Plant Sci. 22:583-595.

Levy, A., Salas Gonzalez, I., Mittelviefhaus, M., Clingenpeel, S., Herrera Paredes, S., Miao, J., Wang, K., Devescovi, G., Stillman, K., Monteiro, F., Rangel Alvarez, B., Lundberg, D. S., Lu, T.-Y., Lebeis, S., Jin, Z., McDonald, M., Klein, A. P., Feltcher, M. E., Rio, T. G., Grant, S. R., Doty, S. L., Ley, R. E., Zhao, B., Venturi, V., Pelletier, D. A., Vorholt, J. A., Tringe, S. G., Woyke, T., and Dangl, J. L. 2018. Genomic features of bacterial adaptation to plants. Nat. Genet. 50:138-150.

Li, J., Li, L., Pang, Z., Kolbasov, V. G., Ehsani, R., Carter, E. W., and Wang, N. 2019a. Developing citrus huanglongbing (HLB) management strategies based on the severity of symptoms in HLB-endemic citrus-producing regions. Phytopathology 109:582-592.

Li, J., Pang, Z., Duan, S., Lee, D., Kolbasov, V., and Wang, N. 2019b. The in planta effective concentration of oxytetracycline against 'Candidatus Liberibacter asiaticus' for suppression of citrus huanglongbing. Phytopathology 109:2046-2054.

Li, J., Pang, Z., Trivedi, P., Zhou, X., Ying, X., Jia, H., and Wang, N. 2017. 'Candidatus Liberibacter asiaticus' encodes a functional salicylic acid (SA) hydroxylase that degrades SA to suppress plant defenses. Mol. PlantMicrobe Interact. 30:620-630.

Liu, C. Y., Zhang, F., Zhang, D. J., Srivastava, A. K., Wu, Q. S., and Zou, Y. N. 2018. Mycorrhiza stimulates root-hair growth and IAA synthesis and transport in trifoliate orange under drought stress. Sci. Rep. 8:1978.

Liu, C.-Y., Zou, Y.-N., Zhang, D.-J., Shu, B., and Wu, Q.-S. 2019. Mycorrhizae and tolerance of abiotic stress in citrus plants. Pages 465-487 in: Biofertilizers for Sustainable Agriculture and Environment. B. Giri, R. Prasad, Q.-S. Wu, and A. Varma, eds. Springer International Publishing, Cham, Switzerland

Liu, H., Brettell, L. E., and Singh, B. 2020. Linking the phyllosphere microbiome to plant health. Trends Plant Sci. 25:841-844.

López-Ráez, J. A., Pozo, M. J., and García-Garrido, J. M. 2011. Strigolactones: A cry for help in the rhizosphere. Botany 89:513-522.

Mankau, R., and Gaspard, J. T. 1986. Nematophagous fungi associated with Tylenchulus semipenetrans and the citrus rhizosphere. Nematologica 32: 359-363. 
Mauchline, T., and Malone, J. 2017. Life in earth-The root microbiome to the rescue? Curr. Opin. Microbiol. 37:23-28.

Mendes, R., Garbeva, P., and Raaijmakers, J. M. 2013. The rhizosphere microbiome: Significance of plant beneficial, plant pathogenic, and human pathogenic microorganisms. FEMS Microbiol. Rev. 37:634-663.

Mitter, B., Pfaffenbichler, N., Flavell, R., Compant, S., Antonielli, L., Petric, A., Berninger, T., Naveed, M., Sheibani-Tezerji, R., von Maltzahn, G., and Sessitsch, A. 2017. A new approach to modify plant microbiomes and traits by introducing beneficial bacteria at flowering into progeny seeds. Front. Microbiol. 8:11.

Mueller, U. G., and Sachs, J. L. 2015. Engineering microbiomes to improve plant and animal health. Trends Microbiol. 23:606-617.

Müller, D. B., Vogel, C., Bai, Y., and Vorholt, J. A. 2016. The plant microbiota: Systems-level insights and perspectives. Annu. Rev. Genet. 50:211-234.

Neal, A. L., Ahmad, S., Gordon-Weeks, R., and Ton, J. 2012. Benzoxazinoids in root exudates of maize attract Pseudomonas putida to the rhizosphere. PLoS One 7:e35498.

Nyholm, L., Koziol, A., Marcos, S., Botnen, A. B., Aizpurua, O., Gopalakrishnan, S., Limborg, M. T., Gilbert, M. T. P., and Alberdi, A. 2020. Holo-Omics: Integrated host-microbiota multi-omics for basic and applied biological research. iScience 23:101414.

Ofek-Lalzar, M., Sela, N., Goldman-Voronov, M., Green, S. J., Hadar, Y., and Minz, D. 2014. Niche and host-associated functional signatures of the root surface microbiome. Nat. Commun. 5:4950.

Padhi, E. M. T., Maharaj, N., Lin, S. Y., Mishchuk, D. O., Chin, E., Godfrey, K., Foster, E., Polek, M., Leveau, J. H. J., and Slupsky, C. M. 2019. Metabolome and microbiome signatures in the roots of citrus affected by huanglongbing. Phytopathology 109:2022-2032.

Passera, A., Alizadeh, H., Azadvar, M., Quaglino, F., Alizadeh, A., Casati, P., and Bianco, P. A. 2018. Studies of microbiota dynamics reveals association of "Candidatus Liberibacter Asiaticus" infection with citrus (Citrus sinensis) decline in south of Iran. Int. J. Mol. Sci. 19:1817.

Pérez-Jaramillo, J. E., Carrión, V. J., Bosse, M., Ferrão, L. F. V., de Hollander, M., Garcia, A. A. F., Ramírez, C. A., Mendes, R., and Raaijmakers, J. M. 2017. Linking rhizosphere microbiome composition of wild and domesticated Phaseolus vulgaris to genotypic and root phenotypic traits. ISME J. 11:2244-2257.

Pfeiffer, S., Mitter, B., Oswald, A., Schloter-Hai, B., Schloter, M., Declerck, S., and Sessitsch, A. 2017. Rhizosphere microbiomes of potato cultivated in the High Andes show stable and dynamic core microbiomes with different responses to plant development. FEMS Microbiol. Ecol. 93:fiw242.

Qiu, Z. G., Egidi, E., Liu, H. W., Kaur, S., and Singh, B. K. 2019. New frontiers in agriculture productivity: Optimised microbial inoculants and in situ microbiome engineering. Biotechnol. Adv. 37:107371.

Reinhold-Hurek, B., Bunger, W., Burbano, C. S., Sabale, M., and Hurek, T. 2015. Roots shaping their microbiome: Global hotspots for microbial activity. Annu. Rev. Phytopathol. 53:403-424.

Riera, N., Handique, U., Zhang, Y., Dewdney, M. M., and Wang, N. 2017. Characterization of antimicrobial-producing beneficial bacteria isolated from huanglongbing escape citrus trees. Front. Microbiol. 8:2415.

Riera, N., Wang, H., Li, Y., Li, J. Y., Pelz-Stelinski, K., and Wang, N. 2018. Induced systemic resistance against citrus canker disease by rhizobacteria. Phytopathology 108:1038-1045.

Rudrappa, T., Czymmek, K. J., Pare, P. W., and Bais, H. P. 2008. Rootsecreted malic acid recruits beneficial soil bacteria. Plant Physiol. 148: 1547-1556.

Sagaram, U. S., Deangelis, K. M., Trivedi, P., Andersen, G. L., Lu, S. E., and Wang, N. 2009. Bacterial diversity analysis of huanglongbing pathogen-infected citrus, using phyloChip arrays and 16S rRNA gene clone library sequencing. Appl. Environ. Microbiol. 75:1566-1574.

Schlaeppi, K., and Bulgarelli, D. 2015. The plant microbiome at work. Mol. Plant-Microbe Interact. 28:212-217.

Schlaeppi, K., Dombrowski, N., Oter, R. G., Ver Loren van Themaat, E., and Schulze-Lefert, P. 2014. Quantitative divergence of the bacterial root microbiota in Arabidopsis thaliana relatives. Proc. Natl. Acad. Sci. U.S.A. 111:585-592.

Sessitsch, A., and Mitter, B. 2015. 21st Century agriculture: Integration of plant microbiomes for improved crop production and food security. Microb. Biotechnol. 8:32-33.

Sessitsch, A., Pfaffenbichler, N., and Mitter, B. 2019. Microbiome applications from lab to field: Facing complexity. Trends Plant Sci. 24:194-198.

Song, C. X., Zhu, F., Carrion, V. J., and Cordovez, V. 2020. Beyond plant microbiome composition: Exploiting microbial functions and plant traits via integrated approaches. Front. Bioeng. Biotechnol. 8:896.
Song, L., and Xie, K. 2020. Engineering CRISPR/Cas9 to mitigate abundant host contamination for $16 \mathrm{~S}$ rRNA gene-based amplicon sequencing. Microbiome 8:80.

Sundin, G. W., Wang, N., Charkowski, A. O., Castiblanco, L. F., Jia, H., and Zhao, Y. 2016. Perspectives on the transition from bacterial phytopathogen genomics studies to applications enhancing disease management: From promise to practice. Phytopathology 106:1071-1082.

Timmusk, S., Behers, L., Muthoni, J., Muraya, A., and Aronsson, A. C. 2017. Perspectives and challenges of microbial application for crop improvement. Front. Plant Sci. 8:49.

Toju, H., Peay, K. G., Yamamichi, M., Narisawa, K., Hiruma, K., Naito, K., Fukuda, S., Ushio, M., Nakaoka, S., Onoda, Y., Yoshida, K., Schlaeppi, K., Bai, Y., Sugiura, R., Ichihashi, Y., Minamisawa, K., and Kiers, E. T. 2018. Core microbiomes for sustainable agroecosystems. Nat. Plants 4:247-257.

Trivedi, P., Anderson, I. C., and Singh, B. K. 2013. Microbial modulators of soil carbon storage: Integrating genomic and metabolic knowledge for global prediction. Trends Microbiol. 21:641-651.

Trivedi, P., Duan, Y., and Wang, N. 2010. Huanglongbing, a systemic disease, restructures the bacterial community associated with citrus roots. Appl. Environ. Microbiol. 76:3427-3436.

Trivedi, P., He, Z., Van Nostrand, J. D., Albrigo, G., Zhou, J., and Wang, N. 2012. Huanglongbing alters the structure and functional diversity of microbial communities associated with citrus rhizosphere. ISME J. 6:363-383.

Trivedi, P., Leach, J. E., Tringe, S. G., Sa, T., and Singh, B. K. 2020. Plantmicrobiome interactions: From community assembly to plant health. Nat. Rev. Microbiol. 18:607-621.

Trivedi, P., Schenk, P. M., Wallenstein, M. D., and Singh, B. K. 2017. Tiny microbes, big yields: Enhancing food crop production with biological solutions. Microb. Biotechnol. 10:999-1003.

Trivedi, P., Spann, T., and Wang, N. 2011. Isolation and characterization of beneficial bacteria associated with citrus roots in Florida. Microb. Ecol. 62:324-336

Trivedi, P., Trivedi, C., Grinyer, J., Anderson, I. C., and Singh, B. K. 2016. Harnessing host-vector microbiome for sustainable plant disease management of phloem-limited bacteria. Front. Plant Sci. 7:1423.

van der Heijden, M. G. A., and Schlaeppi, K. 2015. Root surface as a frontier for plant microbiome research. Proc. Natl. Acad. Sci. U.S.A. 112:2299-2300.

Vannier, N., Agler, M., and Hacquard, S. 2019. Microbiota-mediated disease resistance in plants. PLoS Pathog. 15:e1007740.

Verbon, E. H., and Liberman, L. M. 2016. Beneficial microbes affect endogenous mechanisms controlling root development. Trends Plant Sci. 21:218-229.

Vorholt, J. A. 2012. Microbial life in the phyllosphere. Nat. Rev. Microbiol. 10:828-840.

Vorholt, J. A., Vogel, C., Carlström, C. I., and Müller, D. B. 2017. Establishing causality: Opportunities of synthetic communities for plant microbiome research. Cell Host Microbe 22:142-155.

Walters, W. A., Jin, Z., Youngblut, N., Wallace, J. G., Sutter, J., Zhang, W., Gonzalez-Pena, A., Peiffer, J., Koren, O., Shi, Q. J., Knight, R., del Rio, T. G., Tringe, S. G., Buckler, E. S., Dangl, J. L., and Ley, R. E. 2018. Large-scale replicated field study of maize rhizosphere identifies heritable microbes. Proc. Natl. Acad. Sci. U.S.A. 115:7368-7373.

Wang, N. 2019. The citrus huanglongbing crisis and potential solutions. Mol. Plant 12:607-609.

Wang, N., Pierson, E. A., Setubal, J. C., Xu, J., Levy, J. G., Zhang, Y., Li, J., Rangel, L. T., and Jr, J. M. 2017a. The Candidatus Liberibacter-host interface: Insights into pathogenesis mechanisms and disease control. Annu. Rev. Phytopathol. 55:451-482.

Wang, N., Stelinski, L. L., Pelz-Stelinski, K. S., Graham, J. H., and Zhang, Y. 2017b. Tale of the huanglongbing disease pyramid in the context of the citrus microbiome. Phytopathology 107:380-387.

Wang, X. L., Wang, M. X., Xie, X. G., Guo, S. Y., Zhou, Y., Zhang, X. B., Yu, N., and Wang, E. T. 2020. An amplification-selection model for quantified rhizosphere microbiota assembly. Sci. Bull. (Beijing) 65:983-986.

Woo, S. L., and Pepe, O. 2018. Microbial consortia: Promising probiotics as plant biostimulants for sustainable agriculture. Front. Plant Sci. 9:1801.

Wu, Y., Qu, M., Pu, X., Lin, J., and Shu, B. 2020. Distinct microbial communities among different tissues of citrus tree Citrus reticulata cv. Chachiensis. Sci. Rep. 10:6068.

Xiong, W., Song, Y., Yang, K., Gu, Y., Wei, Z., Kowalchuk, G. A., Xu, Y., Jousset, A., Shen, Q., and Geisen, S. 2020. Rhizosphere protists are key determinants of plant health. Microbiome 8:27.

$\mathrm{Xu}$, J., and Wang, N. 2019. Where are we going with genomics in plant pathogenic bacteria? Genomics 111:729-736. 
Xu, J., Zhang, Y., Zhang, P., Trivedi, P., Riera, N., Wang, Y., Liu, X., Fan, G., Tang, J., Coletta-Filho, H. D., Cubero, J., Deng, X., Ancona, V., Lu, Z., Zhong, B., Roper, M. C., Capote, N., Catara, V., Pietersen, G., Verniere, C., Al-Sadi, A. M., Li, L., Yang, F., Xu, X., Wang, J., Yang, H., Jin, T., and Wang, N. 2018. The structure and function of the global citrus rhizosphere microbiome. Nat. Commun. 9:4894.

Yang, C. Y., Powell, C. A., Duan, Y. P., Shatters, R., Fang, J. P., and Zhang, M. Q. 2016. Deciphering the bacterial microbiome in huanglongbingaffected citrus treated with thermotherapy and sulfonamide antibiotics. PLoS One 11:e0155472.

Yaseen, T., and D'Onghia, A. M. 2012. Fusarium spp. associated to citrus dry root rot: An emerging issue for Mediterranean citriculture. Acta Hortic. 940:647-655.

Yeoh, Y. K., Dennis, P. G., Paungfoo-Lonhienne, C., Weber, L., Brackin, R., Ragan, M. A., Schmidt, S., and Hugenholtz, P. 2017. Evolutionary conservation of a core root microbiome across plant phyla along a tropical soil chronosequence. Nat. Commun. 8:215.

Yergeau, E., Bell, T. H., Champagne, J., Maynard, C., Tardif, S., Tremblay, J., and Greer, C. W. 2015. Transplanting soil microbiomes leads to lasting effects on willow growth, but not on the rhizosphere microbiome. Front. Microbiol. 6:1436.

Yu, K., Pieterse, C. M. J., Bakker, P., and Berendsen, R. L. 2019. Beneficial microbes going underground of root immunity. Plant Cell Environ. 42: 2860-2870.
Zarraonaindia, I., Owens, S. M., Weisenhorn, P., West, K., HamptonMarcell, J., Lax, S., Bokulich, N. A., Mills, D. A., Martin, G., Taghavi, S., van der Lelie, D., and Gilbert, J. A. 2015. The soil microbiome influences grapevine-associated microbiota. MBio 6:e02527-14.

Zgadzaj, R., Garrido-Oter, R., Jensen, D. B., Koprivova, A., Schulze-Lefert, P., and Radutoiu, S. 2016. Root nodule symbiosis in Lotus japonicus drives the establishment of distinctive rhizosphere, root, and nodule bacterial communities. Proc. Natl. Acad. Sci. U.S.A. 113:E7996-E8005.

Zhang, M., Powell, C. A., Benyon, L. S., Zhou, H., and Duan, Y. 2013. Deciphering the bacterial microbiome of citrus plants in response to 'Candidatus Liberibacter asiaticus'-infection and antibiotic treatments. PLoS One 8:e76331.

Zhang, Y., Xu, J., Wang, E., and Wang, N. 2020. Mechanisms underlying the rhizosphere-to-rhizoplane enrichment of Cellvibrio unveiled by genomecentric metagenomics and metatranscriptomics. Microorganisms 8:583.

Zhang, Y.-C., Zou, Y.-N., Liu, L.-P., and Wu, Q.-S. 2019. Common mycorrhizal networks activate salicylic acid defense responses of trifoliate orange (Poncirus trifoliata). J. Integr. Plant Biol. 61:1099-1111.

Zhang, Y., Xu, J., Riera, N., Jin, T., Li, J., and Wang, N. 2017. Huanglongbing impairs the rhizosphere-to-rhizoplane enrichment process of the citrus root-associated microbiome. Microbiome 5:97.

Zou, Y. N., Wang, P., Liu, C. Y., Ni, Q. D., Zhang, D. J., and Wu, Q. S. 2017. Mycorrhizal trifoliate orange has greater root adaptation of morphology and phytohormones in response to drought stress. Sci. Rep. 7:41134. 